\title{
1,4,7,10 - Tetraazacyclododecane Metal Complexes as Potent Promoters of Carboxyester Hydrolysis under Physiological Conditions
}

\section{Supplementary Information}

1. Crystal data and data collection parameters, atomic positional parameters

page

with standard deviations, bond length, bond angles, torsion angles and

hydrogen bonds of $\left[\mathrm{Zn}_{2} \mathrm{L2}\right] \boldsymbol{\mu}-\mathrm{OH}\left(\mathrm{ClO}_{4}\right)_{3} \cdot \mathrm{CH}_{3} \mathrm{CN} \cdot \mathrm{H}_{2} \mathrm{O}$

2. Calculation of the Molar Extinction Coefficients for para-nitrophenolate

S-9

3. Calculation of the spontaneous hydrolysis of 4-nitrophenyl acetate (NA)

S-11

4. $\mathrm{pH}$ Profiles and species distribution diagrams of the metal complexes

S-14 in aqueous solutions under nitrogen at $25^{\circ} \mathrm{C}$ and $I=0.10$ (TEAP).

4.1. Mononuclear complexes

S-14

4.2. Dinuclear complexes

S-17

4.2.1. $\mathrm{pH}$ titration curves

S-17

4.2.2. Species distribution diagrams

S-20

5. Plots of $\mathrm{k}_{\mathrm{obs}} \mathrm{vs} \mathrm{Zn}(\mathrm{II})$ complex concentration and obtained $k_{\text {cat }}$ values

S-23

5.1. Mononuclear $\mathrm{Zn}(\mathrm{II})$ complexes

S-23

5.2. Dinuclear $\mathrm{Zn}(\mathrm{II})$ complexes

S-25

6. Results obtained from the saturation kinetic curves of $\mathbf{Z n} \mathbf{n}_{2} \mathbf{L}$ 2, $Z \mathbf{n}_{2} \mathbf{L} \mathbf{4}$ and $\mathbf{Z n _ { 2 }} \mathbf{L 5}$

S-26

7. Second-order rate constants $k_{\text {cat } 1,2}\left(\mathrm{M}^{-1} \mathrm{~s}^{-1}\right)$ for $\mathbf{Z} \mathbf{n}_{\mathbf{2}} \mathbf{L} \mathbf{6}$ and $\mathbf{Z} \mathbf{n}_{2} \mathbf{L} \mathbf{7}$

S-27

8. Graphical representation of the relationship between measured $k_{\text {cat } 1,2}$,

S-28

the species-distribution diagram and the calculated $k_{\mathrm{cat} 1}$ and $k_{\mathrm{cat} 2}$ for

$\mathbf{Z n}_{2} \mathbf{L 6}$ and $\mathbf{Z n}_{2} \mathbf{L} 7$ 


\title{
1. Crystal data and data collection parameters, atomic positional parameters with standard deviations, bond length, bond angles, torsion angles and hydrogen bonds of $\left[\mathrm{Zn}_{2} \mathrm{~L} 2\right] \mu$ - $\mathrm{OH}\left(\mathrm{ClO}_{4}\right)_{3} \cdot \mathrm{CH}_{3} \mathrm{CN} \cdot \mathrm{H}_{2} \mathrm{O}$.
}

\author{
Empirical formula ; 20 H42 N11 O2 Zn2, C2 H3 N, 3(Cl O4), H2O \\ Formula weight : 956.81 \\ Crystal size : $0.20 \times 0.12 \times 0.06 \mathrm{~mm}$ \\ Crystal description : plate \\ Crystal colour : translucent colorless \\ Crystal system: Monoclinic \\ Space group : P 21/n \\ Unit cell dimensions

$$
\begin{aligned}
& ; \mathrm{a}=14.9051(8) \text { A } \quad \text { alpha }=90 \text { deg. } \\
& ; \mathrm{b}=10.5525(6) \text { A } \quad \text { beta }=105.687(6) \mathrm{deg} . \\
& ; \mathrm{c}=24.4935(13) \text { A } \quad \text { gamma }=90 \mathrm{deg} .
\end{aligned}
$$

Volume ;3709.0(4) A^3

Z, Calculated density ; $4,1.713 \mathrm{Mg} / \mathrm{m}^{\wedge} 3$

Absorption coefficient $; 1.592 \mathrm{~mm}^{\wedge}-1$

$\mathrm{F}(000) ; 1976$

\section{Data Collection ;}

Measurement device type ;STOE-IPDS diffractometer

Measuremnet method ;rotation

Temperature ;173(1) K

Wavelength ;0.71073 A

Monochromator ; graphite

Theta range for data collection ;2.11 to $25.85 \mathrm{deg}$.

Index ranges $;-18<=\mathrm{h}<=18,-12<=\mathrm{k}<=12,-29<=1<=29$

Reflections collected / unique ;32904 / 7132 [R(int $)=0.1253]$

Reflections greater $\mathrm{I}>4 \backslash \backslash \mathrm{s}(\mathrm{I}) ; 3085$

Absorption correction ;Empirical

Max. and min. transmission; 0.802 and 0.413

\section{Refinement ;}

Refinement method ;Full-matrix least-squares on $\mathrm{F}^{\wedge} 2$

Hydrogen treatment ;mixed

Data / restraints / parameters ;7132 / 0 / 490 
Goodness-of-fit on $\mathrm{F}^{\wedge} 2 ; 0.803$

Final $\mathrm{R}$ indices $[\mathrm{I}>2 \operatorname{sigma}(\mathrm{I})] \quad ; \mathrm{R} 1=0.0597, \mathrm{wR} 2=0.1181$

$\mathrm{R}$ indices (all data) $\quad ; \mathrm{R} 1=0.1459, \mathrm{wR} 2=0.1427$

Absolute structure parameter ;

Largest diff. peak and hole $; 0.916$ and -0.692 e. $\mathrm{A}^{\wedge}-3$

Table 1. Atomic coordinates $\left(\mathrm{x} 10^{\wedge} 4\right)$ and equivalent isotropic displacement parameters $\left(\mathrm{A}^{\wedge} 2 \times 10^{\wedge} 3\right)$. $\mathrm{U}(\mathrm{eq})$ is defined as one third of the trace of the orthogonalized Uij tensor.

$$
\text { ;x } \quad \text { y } \quad ; \mathrm{z} ; \mathrm{U}(\mathrm{eq})
$$

$\mathrm{Zn}(1) ; 2642(1) ; 2382(1) ;-185(1) ; 47(1)$

$\operatorname{Zn}(2) ; 3320(1) ; 411(1) ; 1060(1) ; 43(1)$

$\mathrm{O}(1) ; 1211(3) ;-2347(5) ;-538(2) ; 52(2)$

$\mathrm{O}(2) ; 3087(3) ; 967(5) ; 293(2) ; 44(2)$

$\mathrm{N}(1) ; 2288(5) ; 1950(8) ;-1065(3) ; 77(3)$

$\mathrm{N}(2) ; 860(4) ; 1990(5) ;-513(2) ; 42(2)$

$\mathrm{N}(3) ; 2127(4) ; 4031(6) ; 61(3) ; 50(2)$

$\mathrm{N}(4) ; 3746(5) ; 3461(8) ;-300(4) ; 76(3)$

$\mathrm{N}(5) ; 3345(5) ;-1554(6) ; 1202(2) ; 54(2)$

$\mathrm{N}(6) ; 4721(5) ; 373(8) ; 1498(3) ; 67(3)$

$\mathrm{N}(7) ; 3101(5) ; 1550(6) ; 1682(2) ; 57(2)$

$\mathrm{N}(8) ; 1648(4) ;-300(6) ; 1143(2) ; 53(2)$

$\mathrm{N}(9) ; 1086(4) ; 828(6) ; 316(2) ; 42(2)$

$\mathrm{N}(10) ; 1028(4) ;-180(5) ;-566(2) ; 39(2)$

$\mathrm{N}(11) ; 1417(4) ;-1381(6) ; 299(3) ; 48(2)$

$\mathrm{C}(1) ; 1425(6) ; 2546(10) ;-1350(3) ; 73(4)$

$\mathrm{C}(2) ; 670(6) ; 2038(7) ;-1135(3) ; 49(3)$

C(3);549(5);3101(7);-234(3);42(2)

C(4);1120(5);4254(6);-237(3);42(2)

$\mathrm{C}(5) ; 2717(6) ; 5093(8) ;-39(4) ; 68(3)$

$\mathrm{C}(6) ; 3733(6) ; 4606(11) ; 39(5) ; 94(4)$

C(7);3557(8);3611(12);-920(5);100(5)

$\mathrm{C}(8) ; 3170(8) ; 2438(13) ;-1220(5) ; 96(5)$

C(9);4326(6);-1866(9);1372(4);69(3)

$\mathrm{C}(10) ; 4890(6) ;-896(8) ; 1769(3) ; 62(3)$

$\mathrm{C}(11) ; 4822(7) ; 1436(9) ; 1874(4) ; 74(3)$

C(12);4039(7);1598(10);2133(4);80(4)

Table 2. Bond lengths [A] and angles [deg].

$\mathrm{Zn}(1)-\mathrm{O}(2) ; 1.902(5)$

$\mathrm{Zn}(1)-\mathrm{N}(1) ; 2.125(7)$

$\mathrm{Zn}(1)-\mathrm{N}(3) ; 2.058(6)$

$\mathrm{Zn}(1)-\mathrm{N}(4) ; 2.082(8)$

$\mathrm{Zn}(2)-\mathrm{O}(2) ; 1.909(5)$

$\mathrm{Zn}(2)-\mathrm{N}(5) ; 2.101(6)$

$\mathrm{Zn}(2)-\mathrm{N}(6) ; 2.074(8)$

$\mathrm{Zn}(2)-\mathrm{N}(7) ; 2.036(6)$

$\mathrm{Cl}(1)-\mathrm{O}(4) ; 1.408(10)$

$\mathrm{Cl}(1)-\mathrm{O}(5) ; 1.479(14)$

$\mathrm{Cl}(1)-\mathrm{O}(6) ; 1.330(10)$

$\mathrm{Cl}(1)-\mathrm{O}(7) ; 1.264(16)$
$\mathrm{C}(13) ; 2315(6) ; 1169(8) ; 1918(3) ; 54(3)$

$\mathrm{C}(14) ; 1471(6) ; 793(9) ; 1470(3) ; 63(3)$

C(15);1832(6);-1522(8);1431(4);63(3)

C(16);2844(6);-1827(8);1633(3);62(3)

$\mathrm{C}(17) ; 983(5) ; 833(6) ;-240(3) ; 39(2)$

$\mathrm{C}(18) ; 1209(5) ;-1262(7) ;-270(3) ; 43(2)$

C(19);1350(5);-282(7);556(3);44(2)

C(20);1038(5);-2287(8);-1146(3);55(3)

$\mathrm{N}(21) ; 1853(8) ; 5074(12) ;-2051(6) ; 138(6)$

C(22);2249(8);5971(14);-2053(5);91(5)

C(23);2741(8);7151(10);-2057(4);86(4)

$\mathrm{Cl}(1) ;-421(2) ; 268(2) ; 2595(1) ; 86(1)$

$\mathrm{O}(4) ;-315(7) ;-118(8) ; 3159(4) ; 123(4)$

$\mathrm{O}(5) ;-1257(10) ;-271(11) ; 2191(5) ; 188(7)$

$\mathrm{O}(6) ;-605(11) ; 1503(9) ; 2552(5) ; 223(7)$

$\mathrm{O}(7) ; 295(10) ;-50(20) ; 2445(5) ; 285(11)$

$\mathrm{Cl}(2) ; 1207(2) ; 4595(2) ; 1526(1) ; 80(1)$

$\mathrm{O}(8) ; 1258(10) ; 3870(8) ; 1994(3) ; 167(6)$

$\mathrm{O}(9) ; 1070(8) ; 3835(9) ; 1054(3) ; 147(5)$

$\mathrm{O}(10) ; 375(11) ; 5278(13) ; 1497(5) ; 212(7)$

$\mathrm{O}(11) ; 1818(13) ; 5428(14) ; 1599(8) ; 278(10)$

$\mathrm{Cl}(3) ; 3961(2) ;-1630(2) ;-449(1) ; 72(1)$

$\mathrm{O}(12) ; 4617(6) ;-2188(11) ;-600(4) ; 152(5)$

$\mathrm{O}(13) ; 3691(8) ;-533(8) ;-786(4) ; 157(5)$

$\mathrm{O}(14) ; 4170(20) ;-1533(15) ; 75(6) ; 430(20)$

$\mathrm{O}(15) ; 3305(9) ;-2340(30) ;-520(14) ; 510(20)$

$\mathrm{O}(3) ; 3379(8) ; 4225(8) ; 1315(4) ; 136(4)$
$\mathrm{Cl}(2)-\mathrm{O}(9) ; 1.377(8)$

$\mathrm{Cl}(2)-\mathrm{O}(10) ; 1.419(16)$

$\mathrm{Cl}(2)-\mathrm{O}(8) ; 1.363(8)$

$\mathrm{Cl}(2)-\mathrm{O}(11) ; 1.243(18)$

$\mathrm{Cl}(3)-\mathrm{O}(12) ; 1.279(10)$

$\mathrm{Cl}(3)-\mathrm{O}(13) ; 1.415(9)$

$\mathrm{Cl}(3)-\mathrm{O}(15) ; 1.21(2)$

$\mathrm{Cl}(3)-\mathrm{O}(14) ; 1.241(14)$

$\mathrm{O}(1)-\mathrm{C}(20) ; 1.442(9)$

$\mathrm{O}(1)-\mathrm{C}(18) ; 1.320(9)$

$\mathrm{O}(2)-\mathrm{H}(2 \mathrm{O}) ; 0.88(7)$

$\mathrm{N}(1)-\mathrm{C}(1) ; 1.432(12)$ 
$\mathrm{N}(1)-\mathrm{C}(8) ; 1.552(15)$

$\mathrm{N}(2)-\mathrm{C}(3) ; 1.493(9)$

$\mathrm{N}(2)-\mathrm{C}(17) ; 1.380(8)$

$\mathrm{N}(2)-\mathrm{C}(2) ; 1.473(9)$

$\mathrm{N}(3)-\mathrm{C}(5) ; 1.485(11)$

$\mathrm{N}(3)-\mathrm{C}(4) ; 1.500(10)$

$\mathrm{N}(4)-\mathrm{C}(6) ; 1.469(15)$

$\mathrm{N}(4)-\mathrm{C}(7) ; 1.476(15)$

$\mathrm{N}(5)-\mathrm{C}(9) ; 1.446(12)$

$\mathrm{N}(5)-\mathrm{C}(16) ; 1.477(10)$

$\mathrm{N}(6)-\mathrm{C}(11) ; 1.433(12)$

$\mathrm{N}(6)-\mathrm{C}(10) ; 1.486(12)$

$\mathrm{N}(7)-\mathrm{C}(13) ; 1.495(11)$

$\mathrm{N}(7)-\mathrm{C}(12) ; 1.530(12)$

$\mathrm{N}(8)-\mathrm{C}(14) ; 1.468(11)$

$\mathrm{N}(8)-\mathrm{C}(19) ; 1.385(9)$

$\mathrm{N}(8)-\mathrm{C}(15) ; 1.460(11)$

$\mathrm{N}(9)-\mathrm{C}(17) ; 1.329(9)$

$\mathrm{N}(9)-\mathrm{C}(19) ; 1.322(10)$

$\mathrm{N}(10)-\mathrm{C}(17) ; 1.347(8)$

$\mathrm{N}(10)-\mathrm{C}(18) ; 1.340(9)$

$\mathrm{N}(11)-\mathrm{C}(18) ; 1.349(10)$

$\mathrm{N}(11)-\mathrm{C}(19) ; 1.336(10)$

$\mathrm{N}(1)-\mathrm{H}(1) ; 0.9303$

$\mathrm{N}(3)-\mathrm{H}(3) ; 0.9291$

$\mathrm{N}(4)-\mathrm{H}(4) ; 0.9301$

$\mathrm{N}(5)-\mathrm{H}(5) ; 0.9299$

$\mathrm{N}(6)-\mathrm{H}(6) ; 0.9290$

$\mathrm{N}(7)-\mathrm{H}(7) ; 0.9304$

$\mathrm{N}(21)-\mathrm{C}(22) ; 1.116(19)$

$\mathrm{C}(1)-\mathrm{C}(2) ; 1.467(13)$

C(3)-C(4);1.486(10)

$\mathrm{C}(5)-\mathrm{C}(6) ; 1.561(13)$

$\mathrm{C}(7)-\mathrm{C}(8) ; 1.475(18)$

$\mathrm{C}(9)-\mathrm{C}(10) ; 1.503(12)$

$\mathrm{C}(11)-\mathrm{C}(12) ; 1.481(15)$

C(13)-C(14);1.482(12)

C(15)-C(16);1.490(13)

C(1)-H(1A);0.9889

C(1)-H(1B);0.9901

C(2)-H(2A);0.9897

C(2)-H(2B);0.9905

C(3)-H(3A);0.9896

C(3)-H(3B);0.9907

C(4)-H(4B);0.9916

C(4)-H(4A);0.9905

C(5)-H(5A);0.9903

C(5)-H(5B);0.9903

$\mathrm{C}(6)-\mathrm{H}(6 \mathrm{~A}) ; 0.9888$

C(6)-H(6B);0.9890

C(7)-H(7B);0.9909

C(7)-H(7A);0.9895

C(8)-H(8A);0.9883

C(8)-H(8B);0.9900

C(9)-H(9A);0.9913

C(9)-H(9B);0.9897

C(10)-H(10A);0.9903
C(10)-H(10B);0.9894

C(11)-H(11A);0.9900

C(11)-H(11B);0.9902

$\mathrm{C}(12)-\mathrm{H}(12 \mathrm{~A}) ; 0.9894$

C(12)-H(12B);0.9899

C(13)-H(13A);0.9899

C(13)-H(13B);0.9909

C(14)-H(14A);0.9889

C(14)-H(14B);0.9899

C(15)-H(15A);0.9906

$\mathrm{C}(15)-\mathrm{H}(15 \mathrm{~B}) ; 0.9893$

$\mathrm{C}(16)-\mathrm{H}(16 \mathrm{~B}) ; 0.9906$

$\mathrm{C}(16)-\mathrm{H}(16 \mathrm{~A}) ; 0.9904$

$\mathrm{C}(20)-\mathrm{H}(20 \mathrm{~B}) ; 0.9789$

$\mathrm{C}(20)-\mathrm{H}(20 \mathrm{C}) ; 0.9806$

$\mathrm{C}(20)-\mathrm{H}(20 \mathrm{~A}) ; 0.9802$

$\mathrm{C}(22)-\mathrm{C}(23) ; 1.446(18)$

$\mathrm{C}(23)-\mathrm{H}(23 \mathrm{~B}) ; 0.9793$

$\mathrm{C}(23)-\mathrm{H}(23 \mathrm{C}) ; 0.9786$

C(23)-H(23A);0.9809

$\mathrm{O}(2)-\mathrm{Zn}(1)-\mathrm{N}(1) ; 113.9(3)$

$\mathrm{O}(2)-\mathrm{Zn}(1)-\mathrm{N}(3) ; 125.4(2)$

$\mathrm{O}(2)-\mathrm{Zn}(1)-\mathrm{N}(4) ; 110.9(3)$

$\mathrm{N}(1)-\mathrm{Zn}(1)-\mathrm{N}(3) ; 117.9(3)$

$\mathrm{N}(1)-\mathrm{Zn}(1)-\mathrm{N}(4) ; 88.2(3)$

$\mathrm{N}(3)-\mathrm{Zn}(1)-\mathrm{N}(4) ; 87.0(3)$

$\mathrm{O}(2)-\mathrm{Zn}(2)-\mathrm{N}(5) ; 117.2(2)$

$\mathrm{O}(2)-\mathrm{Zn}(2)-\mathrm{N}(6) ; 113.9(3)$

$\mathrm{O}(2)-\mathrm{Zn}(2)-\mathrm{N}(7) ; 122.2(2)$

$\mathrm{N}(5)-\mathrm{Zn}(2)-\mathrm{N}(6) ; 85.7(3)$

$\mathrm{N}(5)-\mathrm{Zn}(2)-\mathrm{N}(7) ; 117.2(2)$

$\mathrm{N}(6)-\mathrm{Zn}(2)-\mathrm{N}(7) ; 88.1(3)$

$\mathrm{O}(6)-\mathrm{Cl}(1)-\mathrm{O}(7) ; 114.2(12)$

$\mathrm{O}(4)-\mathrm{Cl}(1)-\mathrm{O}(7) ; 109.2(8)$

$\mathrm{O}(4)-\mathrm{Cl}(1)-\mathrm{O}(5) ; 113.3(7)$

$\mathrm{O}(4)-\mathrm{Cl}(1)-\mathrm{O}(6) ; 109.1(7)$

$\mathrm{O}(5)-\mathrm{Cl}(1)-\mathrm{O}(6) ; 101.9(8)$

$\mathrm{O}(5)-\mathrm{Cl}(1)-\mathrm{O}(7) ; 109.2(9)$

$\mathrm{O}(8)-\mathrm{Cl}(2)-\mathrm{O}(10) ; 100.2(8)$

$\mathrm{O}(8)-\mathrm{Cl}(2)-\mathrm{O}(9) ; 110.0(5)$

$\mathrm{O}(9)-\mathrm{Cl}(2)-\mathrm{O}(11) ; 118.0(10)$

$\mathrm{O}(8)-\mathrm{Cl}(2)-\mathrm{O}(11) ; 113.8(10)$

$\mathrm{O}(9)-\mathrm{Cl}(2)-\mathrm{O}(10) ; 108.9(7)$

$\mathrm{O}(10)-\mathrm{Cl}(2)-\mathrm{O}(11) ; 104.1(10)$

$\mathrm{O}(12)-\mathrm{Cl}(3)-\mathrm{O}(15) ; 109.0(14)$

$\mathrm{O}(12)-\mathrm{Cl}(3)-\mathrm{O}(13) ; 109.1(7)$

$\mathrm{O}(12)-\mathrm{Cl}(3)-\mathrm{O}(14) ; 109.8(14)$

$\mathrm{O}(13)-\mathrm{Cl}(3)-\mathrm{O}(15) ; 109.4(15)$

$\mathrm{O}(14)-\mathrm{Cl}(3)-\mathrm{O}(15) ; 100(2)$

$\mathrm{O}(13)-\mathrm{Cl}(3)-\mathrm{O}(14) ; 119.2(9)$

$\mathrm{C}(18)-\mathrm{O}(1)-\mathrm{C}(20) ; 116.8(6)$

$\mathrm{Zn}(1)-\mathrm{O}(2)-\mathrm{Zn}(2) ; 141.9(3)$

$\mathrm{Zn}(2)-\mathrm{O}(2)-\mathrm{H}(2 \mathrm{O}) ; 112(5)$

$\mathrm{Zn}(1)-\mathrm{O}(2)-\mathrm{H}(2 \mathrm{O}) ; 104(5)$

$\mathrm{Zn}(1)-\mathrm{N}(1)-\mathrm{C}(8) ; 100.5(6)$

$\mathrm{C}(1)-\mathrm{N}(1)-\mathrm{C}(8) ; 116.3(8)$

$\mathrm{Zn}(1)-\mathrm{N}(1)-\mathrm{C}(1) ; 110.1(5)$ 
$\mathrm{C}(3)-\mathrm{N}(2)-\mathrm{C}(17) ; 119.3(5)$

$\mathrm{C}(2)-\mathrm{N}(2)-\mathrm{C}(17) ; 119.6(5)$

$\mathrm{C}(2)-\mathrm{N}(2)-\mathrm{C}(3) ; 116.7(5)$

$\mathrm{Zn}(1)-\mathrm{N}(3)-\mathrm{C}(4) ; 113.2(4)$

$\mathrm{Zn}(1)-\mathrm{N}(3)-\mathrm{C}(5) ; 107.8(5)$

$\mathrm{C}(4)-\mathrm{N}(3)-\mathrm{C}(5) ; 111.1(6)$

$\mathrm{C}(6)-\mathrm{N}(4)-\mathrm{C}(7) ; 117.7(9)$

$\mathrm{Zn}(1)-\mathrm{N}(4)-\mathrm{C}(7) ; 105.1(7)$

$\mathrm{Zn}(1)-\mathrm{N}(4)-\mathrm{C}(6) ; 104.0(6)$

$\mathrm{Zn}(2)-\mathrm{N}(5)-\mathrm{C}(16) ; 108.8(5)$

$\mathrm{C}(9)-\mathrm{N}(5)-\mathrm{C}(16) ; 114.7(6)$

$\mathrm{Zn}(2)-\mathrm{N}(5)-\mathrm{C}(9) ; 104.1(5)$

$\mathrm{Zn}(2)-\mathrm{N}(6)-\mathrm{C}(10) ; 105.9(5)$

$\mathrm{Zn}(2)-\mathrm{N}(6)-\mathrm{C}(11) ; 103.5(6)$

$\mathrm{C}(10)-\mathrm{N}(6)-\mathrm{C}(11) ; 116.3(7)$

$\mathrm{Zn}(2)-\mathrm{N}(7)-\mathrm{C}(12) ; 105.0(5)$

$\mathrm{C}(12)-\mathrm{N}(7)-\mathrm{C}(13) ; 112.8(6)$

$\mathrm{Zn}(2)-\mathrm{N}(7)-\mathrm{C}(13) ; 115.6(5)$

$\mathrm{C}(14)-\mathrm{N}(8)-\mathrm{C}(15) ; 117.9(6)$

$\mathrm{C}(14)-\mathrm{N}(8)-\mathrm{C}(19) ; 120.1(6)$

C(15)-N(8)-C(19);118.6(6)

$\mathrm{C}(17)-\mathrm{N}(9)-\mathrm{C}(19) ; 113.4(6)$

$\mathrm{C}(17)-\mathrm{N}(10)-\mathrm{C}(18) ; 113.0(5)$

C(18)-N(11)-C(19);112.4(6)

C(8)-N(1)-H(1);109.78

$\mathrm{Zn}(1)-\mathrm{N}(1)-\mathrm{H}(1) ; 109.86$

$\mathrm{C}(1)-\mathrm{N}(1)-\mathrm{H}(1) ; 109.80$

$\mathrm{C}(4)-\mathrm{N}(3)-\mathrm{H}(3) ; 108.22$

$\mathrm{C}(5)-\mathrm{N}(3)-\mathrm{H}(3) ; 108.15$

$\mathrm{Zn}(1)-\mathrm{N}(3)-\mathrm{H}(3) ; 108.19$

$\mathrm{Zn}(1)-\mathrm{N}(4)-\mathrm{H}(4) ; 109.88$

$\mathrm{C}(6)-\mathrm{N}(4)-\mathrm{H}(4) ; 109.86$

C(7)-N(4)-H(4);109.88

$\mathrm{C}(9)-\mathrm{N}(5)-\mathrm{H}(5) ; 109.72$

$\mathrm{Zn}(2)-\mathrm{N}(5)-\mathrm{H}(5) ; 109.70$

C(16)-N(5)-H(5);109.73

$\mathrm{C}(11)-\mathrm{N}(6)-\mathrm{H}(6) ; 110.23$

C(10)-N(6)-H(6);110.32

$\mathrm{Zn}(2)-\mathrm{N}(6)-\mathrm{H}(6) ; 110.21$

$\mathrm{Zn}(2)-\mathrm{N}(7)-\mathrm{H}(7) ; 107.70$

C(13)-N(7)-H(7);107.64

C(12)-N(7)-H(7);107.65

$\mathrm{N}(1)-\mathrm{C}(1)-\mathrm{C}(2) ; 109.9(7)$

$\mathrm{N}(2)-\mathrm{C}(2)-\mathrm{C}(1) ; 115.6(7)$

$\mathrm{N}(2)-\mathrm{C}(3)-\mathrm{C}(4) ; 113.1(6)$

$\mathrm{N}(3)-\mathrm{C}(4)-\mathrm{C}(3) ; 111.6(6)$

$\mathrm{N}(3)-\mathrm{C}(5)-\mathrm{C}(6) ; 109.2(7)$

$\mathrm{N}(4)-\mathrm{C}(6)-\mathrm{C}(5) ; 111.2(8)$

$\mathrm{N}(4)-\mathrm{C}(7)-\mathrm{C}(8) ; 111.3(10)$

$\mathrm{N}(1)-\mathrm{C}(8)-\mathrm{C}(7) ; 113.6(10)$

$\mathrm{N}(5)-\mathrm{C}(9)-\mathrm{C}(10) ; 112.1(7)$

$\mathrm{N}(6)-\mathrm{C}(10)-\mathrm{C}(9) ; 109.1(7)$

$\mathrm{N}(6)-\mathrm{C}(11)-\mathrm{C}(12) ; 114.0(8)$

$\mathrm{N}(7)-\mathrm{C}(12)-\mathrm{C}(11) ; 111.0(7)$

$\mathrm{N}(7)-\mathrm{C}(13)-\mathrm{C}(14) ; 112.5(6)$

$\mathrm{N}(8)-\mathrm{C}(14)-\mathrm{C}(13) ; 111.9(7)$

$\mathrm{N}(8)-\mathrm{C}(15)-\mathrm{C}(16) ; 113.1(7)$
$\mathrm{N}(5)-\mathrm{C}(16)-\mathrm{C}(15) ; 112.5(6)$

$\mathrm{N}(2)-\mathrm{C}(17)-\mathrm{N}(10) ; 115.9(6)$

$\mathrm{N}(2)-\mathrm{C}(17)-\mathrm{N}(9) ; 117.6(6)$

$\mathrm{N}(9)-\mathrm{C}(17)-\mathrm{N}(10) ; 126.4(6)$

$\mathrm{O}(1)-\mathrm{C}(18)-\mathrm{N}(10) ; 119.8(6)$

$\mathrm{O}(1)-\mathrm{C}(18)-\mathrm{N}(11) ; 113.7(6)$

$\mathrm{N}(10)-\mathrm{C}(18)-\mathrm{N}(11) ; 126.5(7)$

$\mathrm{N}(9)-\mathrm{C}(19)-\mathrm{N}(11) ; 127.6(7)$

$\mathrm{N}(8)-\mathrm{C}(19)-\mathrm{N}(9) ; 116.6(6)$

$\mathrm{N}(8)-\mathrm{C}(19)-\mathrm{N}(11) ; 115.7(7)$

$\mathrm{C}(2)-\mathrm{C}(1)-\mathrm{H}(1 \mathrm{~A}) ; 109.75$

C(2)-C(1)-H(1B);109.68

$\mathrm{N}(1)-\mathrm{C}(1)-\mathrm{H}(1 \mathrm{~B}) ; 109.68$

$\mathrm{N}(1)-\mathrm{C}(1)-\mathrm{H}(1 \mathrm{~A}) ; 109.75$

$\mathrm{H}(1 \mathrm{~A})-\mathrm{C}(1)-\mathrm{H}(1 \mathrm{~B}) ; 108.11$

$\mathrm{N}(2)-\mathrm{C}(2)-\mathrm{H}(2 \mathrm{~B}) ; 108.41$

$\mathrm{N}(2)-\mathrm{C}(2)-\mathrm{H}(2 \mathrm{~A}) ; 108.33$

$\mathrm{H}(2 \mathrm{~A})-\mathrm{C}(2)-\mathrm{H}(2 \mathrm{~B}) ; 107.43$

$\mathrm{C}(1)-\mathrm{C}(2)-\mathrm{H}(2 \mathrm{~A}) ; 108.39$

$\mathrm{C}(1)-\mathrm{C}(2)-\mathrm{H}(2 \mathrm{~B}) ; 108.39$

$\mathrm{N}(2)-\mathrm{C}(3)-\mathrm{H}(3 \mathrm{~A}) ; 108.94$

$\mathrm{C}(4)-\mathrm{C}(3)-\mathrm{H}(3 \mathrm{~B}) ; 109.00$

$\mathrm{N}(2)-\mathrm{C}(3)-\mathrm{H}(3 \mathrm{~B}) ; 109.01$

$\mathrm{C}(4)-\mathrm{C}(3)-\mathrm{H}(3 \mathrm{~A}) ; 109.01$

$\mathrm{H}(3 \mathrm{~A})-\mathrm{C}(3)-\mathrm{H}(3 \mathrm{~B}) ; 107.68$

C(3)-C(4)-H(4B);109.24

$\mathrm{H}(4 \mathrm{~A})-\mathrm{C}(4)-\mathrm{H}(4 \mathrm{~B}) ; 108.02$

$\mathrm{C}(3)-\mathrm{C}(4)-\mathrm{H}(4 \mathrm{~A}) ; 109.33$

$\mathrm{N}(3)-\mathrm{C}(4)-\mathrm{H}(4 \mathrm{~A}) ; 109.33$

$\mathrm{N}(3)-\mathrm{C}(4)-\mathrm{H}(4 \mathrm{~B}) ; 109.23$

$\mathrm{N}(3)-\mathrm{C}(5)-\mathrm{H}(5 \mathrm{~A}) ; 109.85$

$\mathrm{N}(3)-\mathrm{C}(5)-\mathrm{H}(5 \mathrm{~B}) ; 109.78$

$\mathrm{C}(6)-\mathrm{C}(5)-\mathrm{H}(5 \mathrm{~A}) ; 109.86$

C(6)-C(5)-H(5B);109.81

$\mathrm{H}(5 \mathrm{~A})-\mathrm{C}(5)-\mathrm{H}(5 \mathrm{~B}) ; 108.29$

$\mathrm{N}(4)-\mathrm{C}(6)-\mathrm{H}(6 \mathrm{~B}) ; 109.45$

$\mathrm{H}(6 \mathrm{~A})-\mathrm{C}(6)-\mathrm{H}(6 \mathrm{~B}) ; 108.02$

$\mathrm{C}(5)-\mathrm{C}(6)-\mathrm{H}(6 \mathrm{~A}) ; 109.37$

$\mathrm{C}(5)-\mathrm{C}(6)-\mathrm{H}(6 \mathrm{~B}) ; 109.32$

$\mathrm{N}(4)-\mathrm{C}(6)-\mathrm{H}(6 \mathrm{~A}) ; 109.39$

$\mathrm{N}(4)-\mathrm{C}(7)-\mathrm{H}(7 \mathrm{~B}) ; 109.45$

$\mathrm{C}(8)-\mathrm{C}(7)-\mathrm{H}(7 \mathrm{~A}) ; 109.41$

$\mathrm{C}(8)-\mathrm{C}(7)-\mathrm{H}(7 \mathrm{~B}) ; 109.29$

$\mathrm{H}(7 \mathrm{~A})-\mathrm{C}(7)-\mathrm{H}(7 \mathrm{~B}) ; 107.97$

$\mathrm{N}(4)-\mathrm{C}(7)-\mathrm{H}(7 \mathrm{~A}) ; 109.40$

$\mathrm{N}(1)-\mathrm{C}(8)-\mathrm{H}(8 \mathrm{~B}) ; 108.82$

$\mathrm{C}(7)-\mathrm{C}(8)-\mathrm{H}(8 \mathrm{~A}) ; 108.87$

$\mathrm{N}(1)-\mathrm{C}(8)-\mathrm{H}(8 \mathrm{~A}) ; 108.88$

$\mathrm{H}(8 \mathrm{~A})-\mathrm{C}(8)-\mathrm{H}(8 \mathrm{~B}) ; 107.74$

$\mathrm{C}(7)-\mathrm{C}(8)-\mathrm{H}(8 \mathrm{~B}) ; 108.81$

$\mathrm{N}(5)-\mathrm{C}(9)-\mathrm{H}(9 \mathrm{~A}) ; 109.14$

$\mathrm{N}(5)-\mathrm{C}(9)-\mathrm{H}(9 \mathrm{~B}) ; 109.30$

$\mathrm{C}(10)-\mathrm{C}(9)-\mathrm{H}(9 \mathrm{~B}) ; 109.23$

$\mathrm{H}(9 \mathrm{~A})-\mathrm{C}(9)-\mathrm{H}(9 \mathrm{~B}) ; 107.92$

$\mathrm{C}(10)-\mathrm{C}(9)-\mathrm{H}(9 \mathrm{~A}) ; 109.05$

$\mathrm{C}(9)-\mathrm{C}(10)-\mathrm{H}(10 \mathrm{~B}) ; 109.88$

H(10A)-C(10)-H(10B);108.33 
C(9)-C(10)-H(10A);109.87

N(6)-C(10)-H(10A);109.76

$\mathrm{N}(6)-\mathrm{C}(10)-\mathrm{H}(10 \mathrm{~B}) ; 109.89$

$\mathrm{N}(6)-\mathrm{C}(11)-\mathrm{H}(11 \mathrm{~B}) ; 108.67$

$\mathrm{H}(11 \mathrm{~A})-\mathrm{C}(11)-\mathrm{H}(11 \mathrm{~B}) ; 107.62$

C(12)-C(11)-H(11A);108.84

C(12)-C(11)-H(11B); 108.80

$\mathrm{N}(6)-\mathrm{C}(11)-\mathrm{H}(11 \mathrm{~A}) ; 108.68$

C(11)-C(12)-H(12B);109.37

$\mathrm{H}(12 \mathrm{~A})-\mathrm{C}(12)-\mathrm{H}(12 \mathrm{~B}) ; 108.07$

N(7)-C(12)-H(12B);109.47

C(11)-C(12)-H(12A);109.44

N(7)-C(12)-H(12A);109.41

N(7)-C(13)-H(13A);109.11

N(7)-C(13)-H(13B);109.16

H(13A)-C(13)-H(13B);107.83

C(14)-C(13)-H(13B);109.07

C(14)-C(13)-H(13A);109.07

N(8)-C(14)-H(14B);109.17

$\mathrm{N}(8)-\mathrm{C}(14)-\mathrm{H}(14 \mathrm{~A}) ; 109.32$

H(14A)-C(14)-H(14B);107.94

$\mathrm{C}(13)-\mathrm{C}(14)-\mathrm{H}(14 \mathrm{~A}) ; 109.21$

C(13)-C(14)-H(14B);109.25
C(16)-C(15)-H(15A); 108.93

C(16)-C(15)-H(15B); 109.02

$\mathrm{H}(15 \mathrm{~A})-\mathrm{C}(15)-\mathrm{H}(15 \mathrm{~B}) ; 107.65$

$\mathrm{N}(8)-\mathrm{C}(15)-\mathrm{H}(15 \mathrm{~B}) ; 109.09$

$\mathrm{N}(8)-\mathrm{C}(15)-\mathrm{H}(15 \mathrm{~A}) ; 108.91$

$\mathrm{N}(5)-\mathrm{C}(16)-\mathrm{H}(16 \mathrm{~B}) ; 109.09$

$\mathrm{N}(5)-\mathrm{C}(16)-\mathrm{H}(16 \mathrm{~A}) ; 109.15$

H(16A)-C(16)-H(16B); 107.80

C(15)-C(16)-H(16B); 109.13

C(15)-C(16)-H(16A);109.08

$\mathrm{O}(1)-\mathrm{C}(20)-\mathrm{H}(20 \mathrm{C}) ; 109.45$

$\mathrm{O}(1)-\mathrm{C}(20)-\mathrm{H}(20 \mathrm{~B}) ; 109.39$

$\mathrm{H}(20 \mathrm{~B})-\mathrm{C}(20)-\mathrm{H}(20 \mathrm{C}) ; 109.52$

H(20A)-C(20)-H(20B); 109.60

H(20A)-C(20)-H(20C);109.47

$\mathrm{O}(1)-\mathrm{C}(20)-\mathrm{H}(20 \mathrm{~A}) ; 109.41$

$\mathrm{N}(21)-\mathrm{C}(22)-\mathrm{C}(23) ; 178.6(15)$

$\mathrm{C}(22)-\mathrm{C}(23)-\mathrm{H}(23 \mathrm{C}) ; 109.50$

$\mathrm{H}(23 \mathrm{~A})-\mathrm{C}(23)-\mathrm{H}(23 \mathrm{C}) ; 109.54$

$\mathrm{H}(23 \mathrm{~B})-\mathrm{C}(23)-\mathrm{H}(23 \mathrm{C}) ; 109.48$

$\mathrm{H}(23 \mathrm{~A})-\mathrm{C}(23)-\mathrm{H}(23 \mathrm{~B}) ; 109.43$

$\mathrm{C}(22)-\mathrm{C}(23)-\mathrm{H}(23 \mathrm{~A}) ; 109.44$

C(22)-C(23)-H(23B);109.44

Symmetry transformations used to generate equivalent atoms:

Table 3. Anisotropic displacement parameters $\left(\mathrm{A}^{\wedge} 2 \times 10^{\wedge} 3\right)$. The anisotropic displacement factor exponent takes the form: $-2 \mathrm{pi}^{\wedge} 2\left[\mathrm{~h}^{\wedge} 2 \mathrm{a}^{* \wedge} 2 \mathrm{U} 11+\ldots+2 \mathrm{~h} \mathrm{k} \mathrm{a} \mathrm{b}^{*} \mathrm{U} 12\right]$

;U11 ;U22 ;U33 ;U23 ;U13;U12

$\mathrm{Zn}(1) ; 37(1) ; 55(1) ; 50(1) ; 21(1) ; 12(1) ; 6(1)$

$\mathrm{Zn}(2) ; 40(1) ; 48(1) ; 37(1) ; 9(1) ; 7(1) ; 1(1)$

$\mathrm{O}(1) ; 53(3) ; 34(3) ; 64(3) ;-1(3) ; 5(2) ; 2(3)$

$\mathrm{O}(2) ; 52(3) ; 46(3) ; 38(3) ; 10(2) ; 17(2) ; 18(2)$

$\mathrm{N}(1) ; 78(5) ; 107(6) ; 64(4) ; 42(4) ; 48(4) ; 58(5)$

$\mathrm{N}(2) ; 53(4) ; 35(3) ; 37(3) ;-1(2) ; 10(3) ;-2(3)$

$\mathrm{N}(3) ; 47(4) ; 50(4) ; 49(3) ; 5(3) ; 7(3) ;-5(3)$

$\mathrm{N}(4) ; 38(4) ; 70(5) ; 123(7) ; 49(5) ; 28(4) ; 9(4)$

$\mathrm{N}(5) ; 58(4) ; 65(4) ; 35(3) ; 3(3) ; 8(3) ; 18(4)$

$\mathrm{N}(6) ; 57(4) ; 87(5) ; 56(4) ; 6(4) ; 12(3) ;-20(4)$

$\mathrm{N}(7) ; 84(5) ; 43(4) ; 41(3) ;-2(3) ; 14(3) ;-13(3)$

$\mathrm{N}(8) ; 51(4) ; 55(4) ; 49(3) ; 16(3) ; 9(3) ;-7(3)$

$\mathrm{N}(9) ; 43(3) ; 46(4) ; 36(3) ; 2(3) ; 9(3) ;-6(3)$

$\mathrm{N}(10) ; 34(3) ; 34(3) ; 45(3) ;-2(3) ; 4(3) ;-5(3)$

$\mathrm{N}(11) ; 42(4) ; 44(4) ; 52(4) ; 9(3) ; 2(3) ;-10(3)$

$\mathrm{C}(1) ; 88(7) ; 93(7) ; 42(4) ; 11(5) ; 22(4) ;-3(6)$

$\mathrm{C}(2) ; 68(5) ; 37(4) ; 34(4) ; 1(3) ;-1(4) ; 2(4)$

$\mathrm{C}(3) ; 42(4) ; 43(4) ; 42(4) ; 0(3) ; 11(3) ;-3(3)$

$\mathrm{C}(4) ; 37(4) ; 39(4) ; 49(4) ; 2(3) ; 10(3) ; 2(3)$

C(5);50(5);46(5);99(7);17(5);4(5);-9(4)

$\mathrm{C}(6) ; 43(5) ; 81(7) ; 149(10) ; 52(8) ; 9(6) ;-20(6)$

C(7);102(9);103(9);124(10);71(8);78(8);34(7)

C(8);94(8);120(10);96(7);57(8);64(7);50(8)

$\mathrm{C}(9) ; 66(6) ; 83(6) ; 53(5) ; 3(5) ; 10(4) ; 15(5)$

$\mathrm{C}(10) ; 51(5) ; 80(6) ; 46(4) ; 15(4) ; 0(4) ; 21(5)$

$\mathrm{C}(11) ; 64(6) ; 65(6) ; 80(6) ; 20(5) ;-2(5) ;-14(5)$
$\mathrm{C}(12) ; 103(8) ; 75(7) ; 50(5) ;-4(5) ; 1(5) ;-4(6)$

$\mathrm{C}(13) ; 63(5) ; 61(5) ; 38(4) ; 9(4) ; 13(4) ; 26(4)$

$\mathrm{C}(14) ; 54(5) ; 91(7) ; 50(5) ; 5(4) ; 23(4) ; 17(5)$

$\mathrm{C}(15) ; 69(6) ; 62(5) ; 54(5) ; 19(4) ; 12(4) ;-10(5)$

$\mathrm{C}(16) ; 77(6) ; 49(5) ; 57(5) ; 13(4) ; 11(4) ;-4(5)$

$\mathrm{C}(17) ; 29(4) ; 36(4) ; 52(4) ; 0(3) ; 9(3) ;-10(3)$

$\mathrm{C}(18) ; 30(4) ; 39(4) ; 55(4) ; 0(3) ; 3(3) ;-7(3)$

C(19);35(4);43(4);51(4);8(4);7(3);-8(4)

C(20);51(5);46(5);63(5);-13(4);5(4);7(4)

$\mathrm{N}(21) ; 84(8) ; 101(9) ; 217(14) ; 31(9) ; 18(8) ;-4(7)$

$\mathrm{C}(22) ; 58(7) ; 100(9) ; 103(8) ; 19(7) ; 1(6) ; 13(7)$

$\mathrm{C}(23) ; 90(7) ; 82(7) ; 86(7) ; 2(6) ; 26(6) ; 2(6)$

$\mathrm{Cl}(1) ; 128(2) ; 46(1) ; 104(2) ;-2(1) ; 63(2) ;-3(2)$

$\mathrm{O}(4) ; 177(9) ; 114(7) ; 104(6) ;-1(5) ; 84(6) ;-4(6)$

$\mathrm{O}(5) ; 277(15) ; 162(10) ; 149(9) ;-94(8) ; 100(9) ;-131(10)$

$\mathrm{O}(6) ; 318(17) ; 83(7) ; 155(9) ;-44(6) ;-128(10) ; 44(8)$

$\mathrm{O}(7) ; 218(13) ; 530(30) ; 157(10) ; 189(15) ; 136(10)$;

$210(17)$

$\mathrm{Cl}(2) ; 124(2) ; 41(1) ; 56(1) ;-7(1) ;-9(1) ; 1(2)$

$\mathrm{O}(8) ; 335(16) ; 88(6) ; 68(5) ; 13(4) ; 39(7) ; 83(8)$

$\mathrm{O}(9) ; 259(12) ; 129(7) ; 59(4) ;-41(5) ; 53(6) ;-64(8)$

$\mathrm{O}(10) ; 265(16) ; 171(11) ; 151(10) ;-11(8) ;-$

29(9);117(12)

$\mathrm{O}(11) ; 310(20) ; 183(12) ; 390(20)$;

$-141(15) ; 179(18) ;-189(14)$

$\mathrm{Cl}(3) ; 83(2) ; 63(1) ; 89(2) ; 28(1) ; 54(1) ; 26(1)$ 
$\mathrm{O}(12) ; 137(7) ; 213(11) ; 129(7) ; 78(7) ; 75(6) ; 118(8)$

$\mathrm{O}(13) ; 237(11) ; 78(6) ; 181(9) ; 70(6) ; 101(9) ; 79(7)$

$\mathrm{O}(14) ; 1030(60) ; 192(14) ; 118(9) ; 29(10) ; 260(20) ; 2$

$30(30)$

$\mathrm{O}(15) ; 90(9) ; 570(40) ; 840(50) ; 620(40) ; 62(17)$;

Table 4. Hydrogen coordinates ( $\left.\times 10^{\wedge} 4\right)$ and isotropic displacement parameters $\left(\mathrm{A}^{\wedge} 2 \times 10^{\wedge} 3\right)$.

$$
\text { ;x } \quad ; \mathrm{y} \quad ; \mathrm{z} \quad ; \mathrm{U}(\mathrm{eq})
$$

$\mathrm{H}(1) ; 2237 ; 1077 ;-1117 ; 93$

H(1A);1475;3472;-1287;88

H(1B);1286;2389;-1763;88

$\mathrm{H}(2 \mathrm{~A}) ; 107 ; 2562 ;-1287 ; 59$

H(2B);525;1169;-1286;59

$\mathrm{H}(2 \mathrm{O}) ; 3390(50) ; 510(70) ; 100(30) ; 53$

$\mathrm{H}(3) ; 2187 ; 3983 ; 448 ; 60$

$\mathrm{H}(3 \mathrm{~A}) ; 580 ; 2877 ; 163 ; 51$

$\mathrm{H}(3 \mathrm{~B}) ;-110 ; 3291 ;-431 ; 51$

$\mathrm{H}(4) ; 4304 ; 3028 ;-158 ; 91$

$\mathrm{H}(4 \mathrm{~A}) ; 1062 ; 4511 ;-634 ; 51$

$\mathrm{H}(4 \mathrm{~B}) ; 880 ; 4956 ;-47 ; 51$

$\mathrm{H}(5) ; 3056 ;-1971 ; 866 ; 64$

$\mathrm{H}(5 \mathrm{~A}) ; 2464 ; 5428 ;-428 ; 82$

$\mathrm{H}(5 \mathrm{~B}) ; 2716 ; 5787 ; 233 ; 82$

$\mathrm{H}(6) ; 5087 ; 483 ; 1249 ; 81$

H(6A);4020;4416;444;113

$\mathrm{H}(6 \mathrm{~B}) ; 4106 ; 5278 ;-77 ; 113$

H(7);2974;2361;1532;68

H(7A);4142;3833;-1015;120

H(7B);3109;4314;-1049;120

$\mathrm{H}(8 \mathrm{~A}) ; 3013 ; 2593 ;-1633 ; 115$

$\mathrm{H}(8 \mathrm{~B}) ; 3654 ; 1770 ;-1129 ; 115$

H(9A);4410;-2704;1562;82

Table 5. Torsion angles [deg]
$17(14)$

$\mathrm{O}(3) ; 199(10) ; 90(6) ; 101(6) ; 6(5) ; 11(6) ; 5(6)$
$\mathrm{H}(9 \mathrm{~B}) ; 4559 ;-1929 ; 1031 ; 82$
$\mathrm{H}(10 \mathrm{~A}) ; 5561 ;-1108 ; 1855 ; 74$
$\mathrm{H}(10 \mathrm{~B}) ; 4709 ;-892 ; 2129 ; 74$
$\mathrm{H}(11 \mathrm{~A}) ; 5407 ; 1335 ; 2180 ; 88$
$\mathrm{H}(11 \mathrm{~B}) ; 4881 ; 2215 ; 1661 ; 88$
$\mathrm{H}(12 \mathrm{~A}) ; 4062 ; 919 ; 2415 ; 96$
$\mathrm{H}(12 \mathrm{~B}) ; 4103 ; 2422 ; 2333 ; 96$
$\mathrm{H}(13 \mathrm{~A}) ; 2158 ; 1886 ; 2136 ; 65$
$\mathrm{H}(13 \mathrm{~B}) ; 2517 ; 450 ; 2183 ; 65$
$\mathrm{H}(14 \mathrm{~A}) ; 1258 ; 1517 ; 1211 ; 76$
$\mathrm{H}(14 \mathrm{~B}) ; 967 ; 578 ; 1647 ; 76$
$\mathrm{H}(15 \mathrm{~A}) ; 1565 ;-1517 ; 1760 ; 75$
$\mathrm{H}(15 \mathrm{~B}) ; 1513 ;-2196 ; 1169 ; 75$
$\mathrm{H}(16 \mathrm{~A}) ; 2918 ;-2736 ; 1736 ; 75$

$\mathrm{H}(16 \mathrm{~B}) ; 3127 ;-1327 ; 1979 ; 75$
$\mathrm{H}(20 \mathrm{~A}) ; 424 ;-1909 ;-1312 ; 67$
$\mathrm{H}(20 \mathrm{~B}) ; 1519 ;-1768 ;-1241 ; 67$
$\mathrm{H}(20 \mathrm{C}) ; 1053 ;-3145 ;-1297 ; 67$
$\mathrm{H}(23 \mathrm{~A}) ; 2306 ; 7792 ;-2267 ; 103$
$\mathrm{H}(23 \mathrm{~B}) ; 3241 ; 7021 ;-2241 ; 103$
$\mathrm{H}(23 \mathrm{C}) ; 3008 ; 7439 ;-1667 ; 103$

$\begin{array}{lc}\mathrm{N}(1)-\mathrm{Zn}(1)-\mathrm{O}(2)-\mathrm{Zn}(2) ; & -164.3(4) \\ \mathrm{N}(3)-\mathrm{Zn}(1)-\mathrm{O}(2)-\mathrm{Zn}(2) ; & -3.6(6) \\ \mathrm{N}(4)-\mathrm{Zn}(1)-\mathrm{O}(2)-\mathrm{Zn}(2) ; & 98.0(5) \\ \mathrm{O}(2)-\mathrm{Zn}(1)-\mathrm{N}(1)-\mathrm{C}(1) ; & 136.5(6) \\ \mathrm{O}(2)-\mathrm{Zn}(1)-\mathrm{N}(1)-\mathrm{C}(8) ; & -100.2(6) \\ \mathrm{N}(3)-\mathrm{Zn}(1)-\mathrm{N}(1)-\mathrm{C}(1) ; & -25.8(7) \\ \mathrm{N}(3)-\mathrm{Zn}(1)-\mathrm{N}(1)-\mathrm{C}(8) ; & 97.5(6) \\ \mathrm{N}(4)-\mathrm{Zn}(1)-\mathrm{N}(1)-\mathrm{C}(1) ; & -111.4(7) \\ \mathrm{N}(4)-\mathrm{Zn}(1)-\mathrm{N}(1)-\mathrm{C}(8) ; & 11.8(7) \\ \mathrm{O}(2)-\mathrm{Zn}(1)-\mathrm{N}(3)-\mathrm{C}(4) ; & -116.2(5) \\ \mathrm{O}(2)-\mathrm{Zn}(1)-\mathrm{N}(3)-\mathrm{C}(5) ; & 120.5(5) \\ \mathrm{N}(1)-\mathrm{Zn}(1)-\mathrm{N}(3)-\mathrm{C}(4) ; & 43.8(6) \\ \mathrm{N}(1)-\mathrm{Zn}(1)-\mathrm{N}(3)-\mathrm{C}(5) ; & -79.5(6) \\ \mathrm{N}(4)-\mathrm{Zn}(1)-\mathrm{N}(3)-\mathrm{C}(4) ; & 130.2(5) \\ \mathrm{N}(4)-\mathrm{Zn}(1)-\mathrm{N}(3)-\mathrm{C}(5) ; & 6.9(6) \\ \mathrm{O}(2)-\mathrm{Zn}(1)-\mathrm{N}(4)-\mathrm{C}(6) ; & -107.1(6) \\ \mathrm{O}(2)-\mathrm{Zn}(1)-\mathrm{N}(4)-\mathrm{C}(7) ; & 128.5(6) \\ \mathrm{N}(1)-\mathrm{Zn}(1)-\mathrm{N}(4)-\mathrm{C}(6) ; & 137.9(7) \\ \mathrm{N}(1)-\mathrm{Zn}(1)-\mathrm{N}(4)-\mathrm{C}(7) ; & 13.6(7) \\ \mathrm{N}(3)-\mathrm{Zn}(1)-\mathrm{N}(4)-\mathrm{C}(6) ; & 19.8(6) \\ \mathrm{N}(3)-\mathrm{Zn}(1)-\mathrm{N}(4)-\mathrm{C}(7) ; & -104.5(7)\end{array}$




\begin{tabular}{|c|c|}
\hline $\mathrm{N}(5)-\mathrm{Zn}(2)-\mathrm{O}(2)-\mathrm{Zn}(1)$ & $156.9(4)$ \\
\hline $\mathrm{N}(6)-\mathrm{Zn}(2)-\mathrm{O}(2)-\mathrm{Zn}(1)$ & $-105.3(5)$ \\
\hline $\mathrm{N}(7)-\mathrm{Zn}(2)-\mathrm{O}(2)-\mathrm{Zn}(1)$ & $-1.7(6)$ \\
\hline $\mathrm{O}(2)-\mathrm{Zn}(2)-\mathrm{N}(5)-\mathrm{C}(9)$ & $99.6(5)$ \\
\hline $\mathrm{O}(2)-\mathrm{Zn}(2)-\mathrm{N}(5)-\mathrm{C}(16)$ & $-137.8(4)$ \\
\hline $\mathrm{N}(6)-\mathrm{Zn}(2)-\mathrm{N}(5)-\mathrm{C}(9)$ & $-15.2(5)$ \\
\hline $\mathrm{N}(6)-\mathrm{Zn}(2)-\mathrm{N}(5)-\mathrm{C}(16)$ & $107.4(5)$ \\
\hline $\mathrm{N}(7)-\mathrm{Zn}(2)-\mathrm{N}(5)-\mathrm{C}(9)$ & $-100.8(5)$ \\
\hline $\mathrm{N}(7)-\mathrm{Zn}(2)-\mathrm{N}(5)-\mathrm{C}(16)$ & $21.8(6)$ \\
\hline $\mathrm{O}(2)-\mathrm{Zn}(2)-\mathrm{N}(6)-\mathrm{C}(10)$ & $-130.4(5)$ \\
\hline $\mathrm{O}(2)-\mathrm{Zn}(2)-\mathrm{N}(6)-\mathrm{C}(11)$ & $106.8(6)$ \\
\hline $\mathrm{N}(5)-\mathrm{Zn}(2)-\mathrm{N}(6)-\mathrm{C}(10)$ & $-12.5(5)$ \\
\hline $\mathrm{N}(5)-\mathrm{Zn}(2)-\mathrm{N}(6)-\mathrm{C}(11)$ & $-135.3(6)$ \\
\hline $\mathrm{N}(7)-\mathrm{Zn}(2)-\mathrm{N}(6)-\mathrm{C}(10)$ & $105.0(5)$ \\
\hline $\mathrm{N}(7)-\mathrm{Zn}(2)-\mathrm{N}(6)-\mathrm{C}(11)$ & $-17.8(6)$ \\
\hline $\mathrm{O}(2)-\mathrm{Zn}(2)-\mathrm{N}(7)-\mathrm{C}(12)$ & $-123.4(5)$ \\
\hline $\mathrm{O}(2)-\mathrm{Zn}(2)-\mathrm{N}(7)-\mathrm{C}(13) ;$ & $111.5(5)$ \\
\hline $\mathrm{N}(5)-\mathrm{Zn}(2)-\mathrm{N}(7)-\mathrm{C}(12)$ & $78.1(6)$ \\
\hline $\mathrm{N}(5)-\mathrm{Zn}(2)-\mathrm{N}(7)-\mathrm{C}(13)$ & $-47.0(6)$ \\
\hline $\mathrm{N}(6)-\mathrm{Zn}(2)-\mathrm{N}(7)-\mathrm{C}(12)$ & $-6.1(5)$ \\
\hline $\mathrm{N}(6)-\mathrm{Zn}(2)-\mathrm{N}(7)-\mathrm{C}(13)$ & $-131.2(5)$ \\
\hline $\mathrm{C}(20)-\mathrm{O}(1)-\mathrm{C}(18)-\mathrm{N}(10)$ & $1.6(10)$ \\
\hline $\mathrm{C}(20)-\mathrm{O}(1)-\mathrm{C}(18)-\mathrm{N}(11)$ & $-177.1(6)$ \\
\hline $\mathrm{Zn}(1)-\mathrm{N}(1)-\mathrm{C}(8)-\mathrm{C}(7) ;$ & $-37.6(10)$ \\
\hline $\mathrm{C}(1)-\mathrm{N}(1)-\mathrm{C}(8)-\mathrm{C}(7) ;$ & $81.3(11)$ \\
\hline $\mathrm{C}(8)-\mathrm{N}(1)-\mathrm{C}(1)-\mathrm{C}(2)$ & $-176.7(8)$ \\
\hline $\mathrm{Zn}(1)-\mathrm{N}(1)-\mathrm{C}(1)-\mathrm{C}(2)$ & $-63.2(8)$ \\
\hline $\mathrm{C}(17)-\mathrm{N}(2)-\mathrm{C}(3)-\mathrm{C}(4) ;$ & $131.7(7)$ \\
\hline $\mathrm{C}(2)-\mathrm{N}(2)-\mathrm{C}(3)-\mathrm{C}(4)$ & $-71.6(8)$ \\
\hline $\mathrm{C}(2)-\mathrm{N}(2)-\mathrm{C}(17)-\mathrm{N}(9)$ & $-175.3(7)$ \\
\hline $\mathrm{C}(3)-\mathrm{N}(2)-\mathrm{C}(17)-\mathrm{N}(9) ;$ & $-19.3(10)$ \\
\hline $\mathrm{C}(3)-\mathrm{N}(2)-\mathrm{C}(2)-\mathrm{C}(1) ;$ & 93.3(9) \\
\hline $\mathrm{C}(2)-\mathrm{N}(2)-\mathrm{C}(17)-\mathrm{N}(10) ;$ & $7.6(10)$ \\
\hline $\mathrm{C}(3)-\mathrm{N}(2)-\mathrm{C}(17)-\mathrm{N}(10)$; & $163.6(6)$ \\
\hline $\mathrm{C}(17)-\mathrm{N}(2)-\mathrm{C}(2)-\mathrm{C}(1) ;$ & $-110.1(8)$ \\
\hline $\mathrm{C}(5)-\mathrm{N}(3)-\mathrm{C}(4)-\mathrm{C}(3)$ & $169.0(6)$ \\
\hline $\mathrm{Zn}(1)-\mathrm{N}(3)-\mathrm{C}(4)-\mathrm{C}(3)$ & $47.6(7)$ \\
\hline $\mathrm{Zn}(1)-\mathrm{N}(3)-\mathrm{C}(5)-\mathrm{C}(6)$ & $-31.1(8)$ \\
\hline $\mathrm{C}(4)-\mathrm{N}(3)-\mathrm{C}(5)-\mathrm{C}(6)$ & $-155.7(7)$ \\
\hline $\mathrm{Zn}(1)-\mathrm{N}(4)-\mathrm{C}(6)-\mathrm{C}(5)$ & $-42.5(9)$ \\
\hline $\mathrm{Zn}(1)-\mathrm{N}(4)-\mathrm{C}(7)-\mathrm{C}(8)$ & $-38.6(11)$ \\
\hline $\mathrm{C}(6)-\mathrm{N}(4)-\mathrm{C}(7)-\mathrm{C}(8)$ & $-153.8(9)$ \\
\hline $\mathrm{C}(7)-\mathrm{N}(4)-\mathrm{C}(6)-\mathrm{C}(5) ;$ & $73.2(11)$ \\
\hline $\mathrm{Zn}(2)-\mathrm{N}(5)-\mathrm{C}(16)-\mathrm{C}(15)$ & $65.6(7)$ \\
\hline $\mathrm{C}(9)-\mathrm{N}(5)-\mathrm{C}(16)-\mathrm{C}(15)$ & $-178.4(7)$ \\
\hline $\mathrm{C}(16)-\mathrm{N}(5)-\mathrm{C}(9)-\mathrm{C}(10) ;$ & $-77.4(9)$ \\
\hline $\mathrm{Zn}(2)-\mathrm{N}(5)-\mathrm{C}(9)-\mathrm{C}(10)$ & $41.3(7)$ \\
\hline $\mathrm{Zn}(2)-\mathrm{N}(6)-\mathrm{C}(11)-\mathrm{C}(12)$ & $40.5(9)$ \\
\hline $\mathrm{C}(11)-\mathrm{N}(6)-\mathrm{C}(10)-\mathrm{C}(9) ;$ & $151.9(8)$ \\
\hline $\mathrm{Zn}(2)-\mathrm{N}(6)-\mathrm{C}(10)-\mathrm{C}(9) ;$ & $37.6(8)$ \\
\hline $\mathrm{C}(10)-\mathrm{N}(6)-\mathrm{C}(11)-\mathrm{C}(12)$ & $-75.2(10)$ \\
\hline $\mathrm{C}(12)-\mathrm{N}(7)-\mathrm{C}(13)-\mathrm{C}(14)$ & $-164.7(7)$ \\
\hline $\mathrm{Zn}(2)-\mathrm{N}(7)-\mathrm{C}(12)-\mathrm{C}(11)$ & $29.2(9)$ \\
\hline $\mathrm{C}(13)-\mathrm{N}(7)-\mathrm{C}(12)-\mathrm{C}(11)$ & $156.0(7)$ \\
\hline $\mathrm{Zn}(2)-\mathrm{N}(7)-\mathrm{C}(13)-\mathrm{C}(14)$ & $-43.8(8)$ \\
\hline $\mathrm{C}(14)-\mathrm{N}(8)-\mathrm{C}(15)-\mathrm{C}(16)$ & $-98.5(8)$ \\
\hline $\mathrm{C}(15)-\mathrm{N}(8)-\mathrm{C}(19)-\mathrm{N}(9) ;$ & $172.2(7)$ \\
\hline
\end{tabular}




$\begin{array}{lc}\text { C(15)-N(8)-C(19)-N(11); } & -11.6(10) \\ \text { C(19)-N(8)-C(14)-C(13); } & -133.0(7) \\ \text { C(15)-N(8)-C(14)-C(13); } & 68.0(9) \\ \text { C(14)-N(8)-C(19)-N(9); } & 13.4(10) \\ \text { C(19)-N(8)-C(15)-C(16); } & 102.2(8) \\ \text { C(14)-N(8)-C(19)-N(11); } & -170.4(7) \\ \text { C(19)-N(9)-C(17)-N(2); } & -169.6(7) \\ \text { C(19)-N(9)-C(17)-N(10); } & 7.2(11) \\ \text { C(17)-N(9)-C(19)-N(11); } & -8.0(11) \\ \text { C(17)-N(9)-C(19)-N(8); } & 167.7(7) \\ \text { C(18)-N(10)-C(17)-N(2); } & 175.9(6) \\ \text { C(17)-N(10)-C(18)-N(11); } & -6.0(11) \\ \text { C(18)-N(10)-C(17)-N(9); } & -1.0(11) \\ \text { C(17)-N(10)-C(18)-O(1); } & 175.4(7) \\ \text { C(18)-N(11)-C(19)-N(9); } & 2.3(11) \\ \text { C(19)-N(11)-C(18)-N(10); } & 5.4(11) \\ \text { C(18)-N(11)-C(19)-N(8); } & -173.4(6) \\ \text { C(19)-N(11)-C(18)-O(1); } & -175.9(6) \\ \text { N(1)-C(1)-C(2)-N(2); } & 48.5(10) \\ \text { N(2)-C(3)-C(4)-N(3); } & -59.2(8) \\ \text { N(3)-C(5)-C(6)-N(4); } & 51.5(11) \\ \text { N(4)-C(7)-C(8)-N(1); } & 54.7(13) \\ \text { N(5)-C(9)-C(10)-N(6); } & -55.7(9) \\ \text { N(6)-C(11)-C(12)-N(7); } & -49.6(11) \\ \text { N(7)-C(13)-C(14)-N(8); } & 60.9(9) \\ \text { N(8)-C(15)-C(16)-N(5); } & -44.8(9) \\ & \end{array}$

Symmetry transformations used to generate equivalent atoms:

Table 6. Hydrogen-bonds [A and deg.].

D-H...A;d(D-H);d(H...A);d(D...A);<(DHA)

$\mathrm{O}(2)-\mathrm{H}(2 \mathrm{O}) \ldots \mathrm{O}(13) ; 0.88(7) ; 2.58(7) ; 3.403(11) ; 156(6)$

$\mathrm{O}(2)-\mathrm{H}(2 \mathrm{O}) \ldots \mathrm{O}(14) ; 0.88(7) ; 2.46(8) ; 3.21(2) ; 144(6)$

$\mathrm{N}(3)-\mathrm{H}(3) \ldots \mathrm{O}(3) ; 0.9291 ; 2.3856 ; 3.140(12) ; 138.19$

$\mathrm{N}(3)-\mathrm{H}(3) \ldots \mathrm{O}(9) ; 0.9291 ; 2.5171 ; 3.242(12) ; 135.11$

$\mathrm{N}(4)-\mathrm{H}(4) \ldots \mathrm{O}(12) \# 1 ; 0.9301 ; 2.2813 ; 3.116(13) ; 149.04$

$\mathrm{N}(5)-\mathrm{H}(5) \ldots \mathrm{N}(11) ; 0.9299 ; 2.5396 ; 3.122(9) ; 120.99$

$\mathrm{N}(6)-\mathrm{H}(6) \ldots \mathrm{O}(12) \# 1 ; 0.9290 ; 2.5175 ; 3.264(13) ; 137.57$

$\mathrm{N}(6)-\mathrm{H}(6) \ldots \mathrm{O}(13) \# 1 ; 0.9290 ; 2.3924 ; 3.302(14) ; 166.29$

$\mathrm{N}(7)-\mathrm{H}(7) \ldots \mathrm{O}(3) ; 0.9304 ; 2.1655 ; 3.025(11) ; 153.12$

$\mathrm{C}(1)-\mathrm{H}(1 \mathrm{~B}) \ldots \mathrm{O}(5) \# 2 ; 0.9901 ; 2.4641 ; 3.129(15) ; 124.14$

$\mathrm{C}(2)-\mathrm{H}(2 \mathrm{~A}) \ldots \mathrm{O}(10) \# 3 ; 0.9897 ; 2.4034 ; 3.238(16) ; 141.66$

$\mathrm{C}(2)-\mathrm{H}(2 \mathrm{~B}) \ldots \mathrm{N}(10) ; 0.9905 ; 2.2324 ; 2.702(9) ; 107.61$

C(3)-H(3A)...O(9); 0.9896; 2.3359; 3.135(10); 137.26

$\mathrm{C}(3)-\mathrm{H}(3 \mathrm{~A}) \ldots \mathrm{N}(9) ; 0.9896 ; 2.2873 ; 2.761(9) ; 108.21$

$\mathrm{C}(4)-\mathrm{H}(4 \mathrm{~A}) . . \mathrm{O}(10) \# 3 ; 0.9905 ; 2.5801 ; 3.319(15) ; 131.35$

$\mathrm{C}(6)-\mathrm{H}(6 \mathrm{~A}) \ldots \mathrm{O}(3) ; 0.9888 ; 2.5704 ; 3.332(15) ; 133.75$

$\mathrm{C}(8)-\mathrm{H}(8 \mathrm{~B}) \ldots \mathrm{O}(13) ; 0.9900 ; 2.5671 ; 3.334(16) ; 134.24$

C(9)-H(9A)...O(6)\#4; $0.9913 ; 2.5479 ; 3.290(15) ; 131.55$

C(9)-H(9B)...O(14); 0.9897; 2.2934; 3.142(18); 143.12

$\mathrm{C}(13)-\mathrm{H}(13 \mathrm{~A}) \ldots \mathrm{O}(8) ; 0.9899 ; 2.4600 ; 3.286(14) ; 140.68$

$\mathrm{C}(14)-\mathrm{H}(14 \mathrm{~A}) \ldots \mathrm{O}(9) ; 0.9889 ; 2.4802 ; 3.372(13) ; 149.84$

$\mathrm{C}(14)-\mathrm{H}(14 \mathrm{~A}) \ldots \mathrm{N}(9) ; 0.9889 ; 2.2574 ; 2.728(9) ; 107.85$

C(14)-H(14B)...O(7); 0.9899; 2.5143; 3.440(17); 155.49

C(15)-H(15B)...N(11); 0.9893; 2.2663; 2.677(12); 103.54 
$\mathrm{C}(16)-\mathrm{H}(16 \mathrm{~A}) \ldots \mathrm{O}(11) \# 5 ; 0.9904 ; 2.5014 ; 3.266(18) ; 133.80$

$\mathrm{C}(16)-\mathrm{H}(16 \mathrm{~B}) . . \mathrm{O}(8) \# 4 ; 0.9906 ; 2.4422 ; 3.348(10) ; 151.76$

$\mathrm{C}(23)-\mathrm{H}(23 \mathrm{~A}) \ldots \mathrm{O}(6) \# 3 ; 0.9809 ; 2.5518 ; 3.396(19) ; 144.24$

C(23)-H(23B)...O(5)\#6; 0.9793; 2.5433; 3.324(17); 136.60

Symmetry transformations used to generate equivalent atoms:

$\# 1-\mathrm{x}+1,-\mathrm{y},-\mathrm{z} \quad \# 2-\mathrm{x},-\mathrm{y},-\mathrm{z} \quad \# 3-\mathrm{x},-\mathrm{y}+1,-\mathrm{z}$

\#4 1/2-x,1/2+y-1,1/2-z \#5 x,y-1,z \#6 1/2+x,1/2-y,1/2+z-1 


\section{Calculation of the Molar Extinction Coefficients for para-nitrophenolate}

The hydrolysis of 4-nitrophenyl acetate (NA) releases $p$-nitrophenolate as a product which can be detected spectrophotometrically. The molar extinction coefficient of the nitrophenol anion varies due to the protonation equilibrium, thus due to the $\mathrm{pH}$ value and the used buffer system. The molar extinction coefficient was determined experimentally for the $\mathrm{pH}$ range 7 to 9 in a buffer system TRIS/HCl (20-80 mM).

For the protonation equilibrium and its equilibrium constant $K_{a}$ applies:

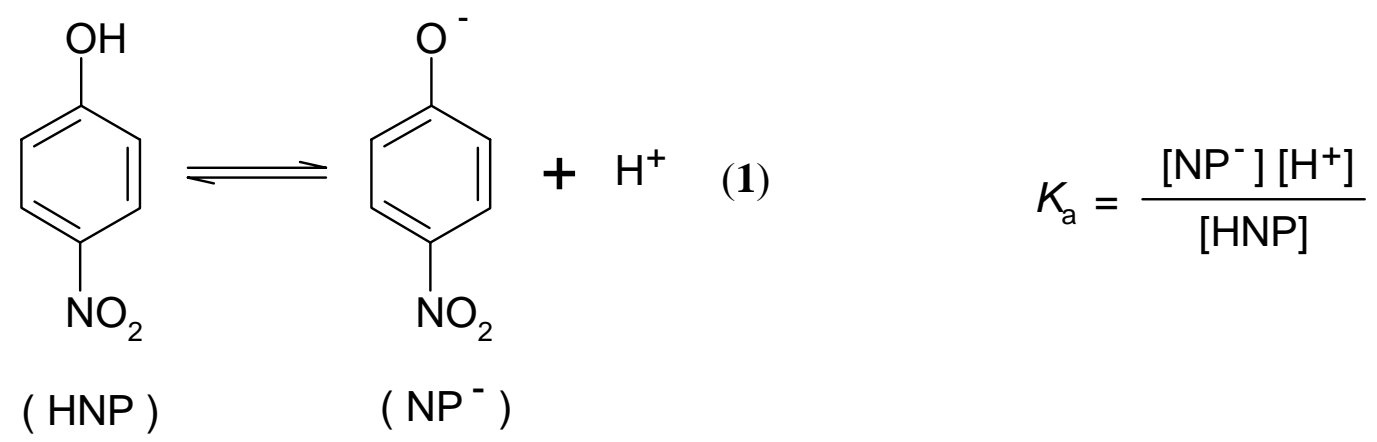

According to the Lambert-Beer law the absorption in diluted solution is:

$$
\text { Abs } \left.=\varepsilon_{\text {obs }} d[\mathrm{HNP}]\right]^{\text {total }}=\varepsilon_{\mathrm{NP}} \mathrm{d}\left[\mathrm{NP}^{-}\right]
$$

where $\varepsilon_{\mathrm{obs}}$ is the measured extinction coefficient of HNP, $\varepsilon_{\mathrm{NP}}$ is the extinction coefficient of the $p$ nitrophenolate ion and d the thickness of the cell. Equations (2) and (3) give equation (4) which describes the relationship between the molar extinction coefficient and the $\mathrm{pH}$ value.

$$
\varepsilon_{\mathrm{obs}}=\frac{\varepsilon_{\mathrm{NP}} K_{\mathrm{a}}}{K_{\mathrm{a}}+\left[\mathrm{H}^{+}\right]}
$$

Plots of $1 / \varepsilon_{\mathrm{obs}}$ versus $\left[\mathrm{H}^{+}\right]$allow the determination of the molar extinction coefficient of the $p$ nitrophenolate for various $\mathrm{pH}$ values and various buffer systems. In the $\mathrm{pH}$ range of 7 to 9 for the buffer system TRIS/HCl the respective $\varepsilon_{\mathrm{obs}}$ values were obtained with a regression coefficient of $\mathrm{R}^{2}>0.9991$ using a dilution series $\left(\mathrm{c}=10^{-4}\right.$ to $5 \cdot 10^{-7} \mathrm{~mol} \mathrm{~L}^{-1} p$-nitrophenol). The $\varepsilon_{\mathrm{obs}}$ values for $400 \mathrm{~nm}$ are summarised in Table 7. 


\begin{tabular}{|c|c|}
\hline $\mathbf{p H}$ & $\varepsilon_{\text {obs }}$ at $\mathbf{4 0 0} \mathbf{~ n m ~}\left[\mathbf{m o l}^{\mathbf{1}} \mathbf{L} \mathbf{~ c m}^{-\mathbf{1}} \mathbf{]}\right.$ \\
\hline 7.01 & 7805 \\
\hline 7.04 & 8201 \\
\hline 7.21 & 9938 \\
\hline 7.28 & 10628 \\
\hline 7.50 & 12665 \\
\hline 7.81 & 15119 \\
\hline 8.11 & 16581 \\
\hline 8.53 & 17602 \\
\hline 8.75 & 17911 \\
\hline 9.01 & 18097 \\
\hline
\end{tabular}

${ }^{a} \Delta \mathrm{pH}= \pm 0.005$

Table 7: $\varepsilon_{\mathrm{obs}}$-values for $p$-nitrophenolate at $400 \mathrm{~nm}\left(25^{\circ} \mathrm{C}, 50 \mathrm{mM}\right.$ TRIS/HCl$)$.

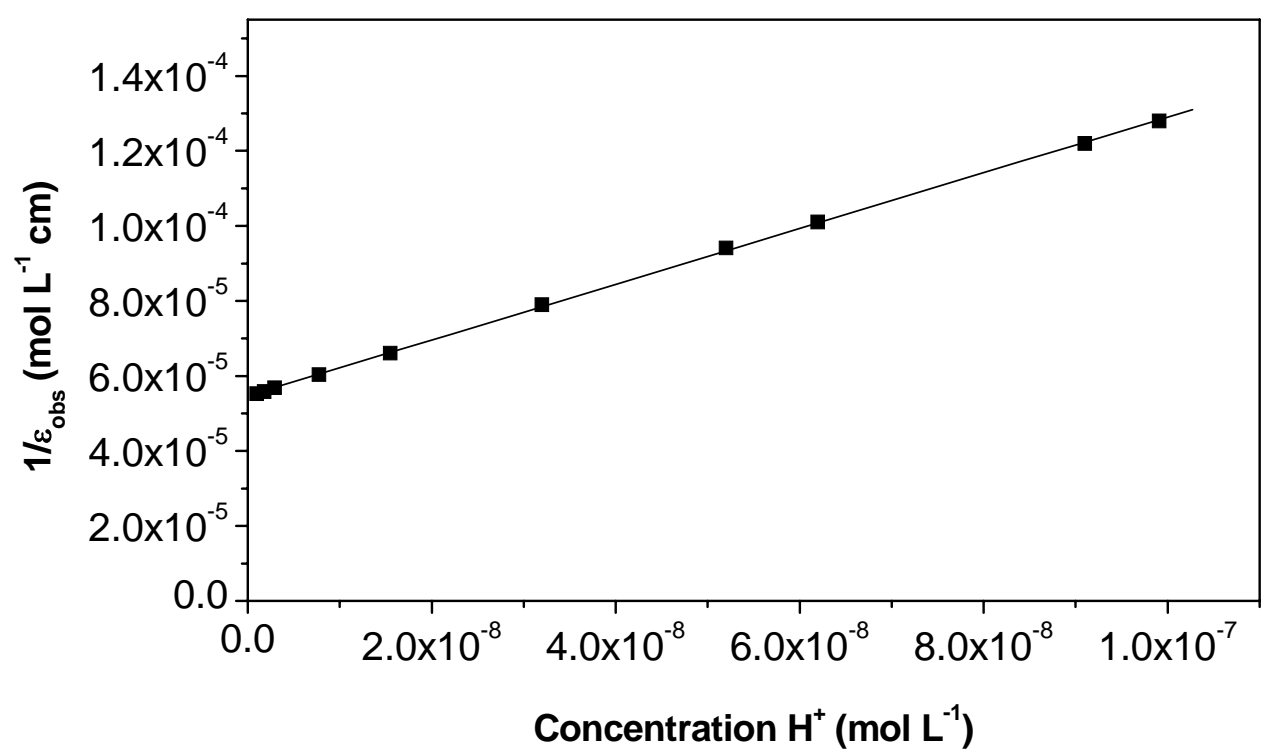

Figure 1: Calculation of the molar extinction coefficient for $p$-nitrophenolate at $400 \mathrm{~nm}$ $\left(25^{\circ} \mathrm{C}, 50 \mathrm{mM}\right.$ TRIS/HCl$)$.

From the slope, respectively the axis segment we can calculate by using equation (4) the equilibrium constant $\left(\mathrm{p} K_{\mathrm{a}}=7.14 \pm 0.01\right)$ as well as the molar extinction coefficient at $400 \mathrm{~nm}$ $\left(\varepsilon_{\mathrm{NP}, 400 \mathrm{~nm}}=18279 \mathrm{~mol}^{-1} \mathrm{~L} \mathrm{~cm}^{-1}\right)$. The value of the equilibrium constant calculated this way 
corresponds to the value from literature ${ }^{1}$. Variations in the buffer concentration (TRIS/HCl 20 and $80 \mathrm{mM}$ ) or in the ionic strength show no significant changes in the molar extinction coefficient. Changes in the region of $\Delta \varepsilon_{\mathrm{NP}} \approx \pm 70 \mathrm{~mol}^{-1} \mathrm{~L} \mathrm{~cm}^{-1}$ were detected.

\section{Calculation of the spontaneous hydrolysis of 4-nitrophenyl acetate (NA)}

The nucleophilic attack of $\mathrm{OH}^{-}$in the used solvent system competes with the metal catalyzed hydrolysis of NA. This spontaneous hydrolysis has to be taken into account when analyzing the reaction kinetics. The spontaneous hydrolysis is a bimolecular reaction, described by equation (5):

$$
v=k_{\mathrm{x}+\mathrm{y}}\left[\mathrm{OH}^{-}\right]^{\mathrm{x}}[\text { Ester }]^{\mathrm{y}}
$$

Under the given reaction conditions the velocity of reaction $v$ is directly proportional to the concentration of the used ester and the concentration of the hydroxide ions. Therefore the spontaneous hydrolysis shows second-order kinetics, with each reactant having a first order dependence. For a constant $\mathrm{pH}$ value equation (5) becomes:

$$
\begin{gathered}
v=\frac{d(\mathrm{Abs})}{d(\mathrm{t}) \varepsilon_{\mathrm{obs}}}=k_{\mathrm{obs}}^{\prime}\left[\text { Ester] }=\left(k_{\mathrm{OH}}\left[\mathrm{OH}^{-}\right]+k_{0}\right)[\text { Ester }]\right. \\
k_{\mathrm{obs}}^{\prime}=k_{0}+k_{\mathrm{OH}}\left[\mathrm{OH}^{-}\right]
\end{gathered}
$$

Equation (7) shows the $k^{\prime}{ }_{\text {obs }}$-value as an additive value. The $k_{\mathrm{OH}}$ value is a second-order velocity constant describing the nucleophilic attack of the $\mathrm{OH}^{-}$ions. The $k_{0}$ value is a first-order constant describing the solvolysis of the ester due to solvent molecules (e.g. water or organic additives).

The use of known values from literature for the spontaneous hydrolysis is not possible, as these constants depend on the reaction conditions (e.g. the type of buffer system used, the ionic strength, the presence of organic additives etc $)^{2}$.

The $k_{\text {obs }}$ value was determined by the initial slope method at constant $\mathrm{pH}$ with various concentrations of NA ([NA] $=2$ to $5 \mathrm{mM})$. The results are presented in Table 8.

\footnotetext{
1 a) J.A. Dean, Lange's Handbook of Chemistry, McGraw-Hill, New York, 1973, Vol.11, Chapter 5; b) Robinson, R.A.; Briggs, A.T. Trans. Faraday Soc. 1955, 51, $901\left(\mathrm{pK}_{\mathrm{a}}=7.149\right.$ at $\left.25^{\circ} \mathrm{C}\right)$.

2 a) J. F. Kirsch, W. P. Jencks, J. Am. Chem. Soc. 1964, 86, 837-846; b) T. C. Bruice, C. L. Schmir, J. Am. Chem. Soc. 1957, 79, 1663-1667; c) W. P. Jencks, M. Gilchrist, J. Am. Chem. Soc. 1968, 90, 2622-2637
} 


\begin{tabular}{|c|c|c|c|c|c|c|c|c|c|}
\hline $\mathrm{pH}^{a}$ & $7.00^{c}$ & 7.20 & 7.34 & 7.52 & 7.82 & 7.93 & $8.00^{c}$ & 8.23 & 8.51 \\
\hline$k_{\text {obs }}^{\prime}\left[10^{-6} \mathrm{~s}^{-1}\right]^{b}$ & 1.50 & 1.87 & 2.46 & 3.30 & 6.08 & 7.32 & 8.94 & 15.17 & 27.02 \\
\hline
\end{tabular}

${ }^{a} \Delta \mathrm{pH}= \pm 0.005 ;{ }^{b} 25.0 \pm 0.1{ }^{\circ} \mathrm{C}, 50 \mathrm{mM}$ TRIS/HCl, $10 \% \mathrm{CH}_{3} \mathrm{CN}, \Delta k^{\prime}{ }_{\mathrm{obs}}= \pm 2.0 \cdot 10^{-8} \mathrm{~s}^{-1}$;

${ }^{c} I=0$ to $50 \mathrm{mM} \mathrm{NaCl}$

Table 8: $k_{\text {obs }}$ values for the spontaneous hydrolysis of NA

From the plot of $k^{\prime}$ obs versus $\left[\mathrm{OH}^{-}\right]$and equation (7) the following results were obtained:

$k_{\mathrm{OH}}=8.16 \pm 0.01 \mathrm{M}^{-1} \mathrm{~s}^{-1}$ and $k_{0}=6.63 \pm 0.02 \cdot 10^{-7} \mathrm{~s}^{-1}$ (Fig. 2)

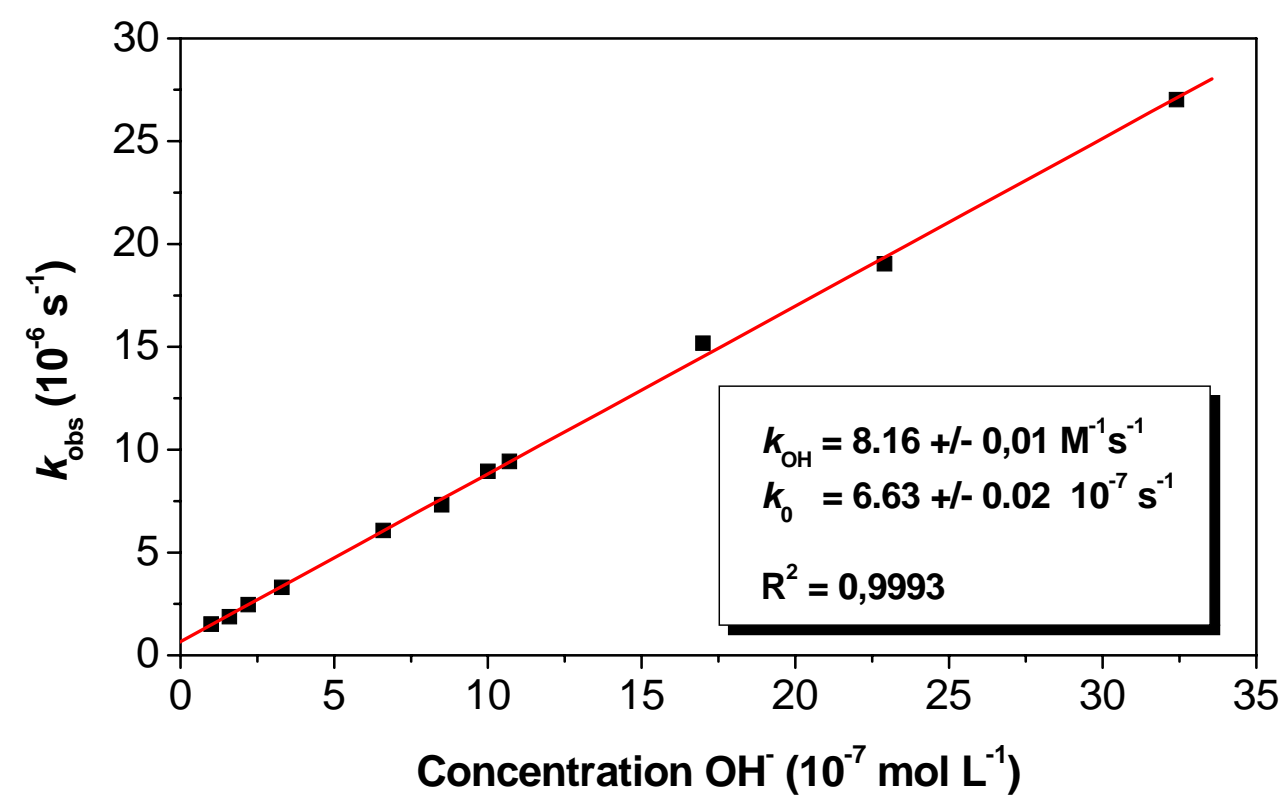

Fig. 2: $k_{\text {obs }}$ versus $\left[\mathrm{OH}^{-}\right]$in the $\mathrm{pH}$ range 7.0 - 8.5.

A variation of the ionic strength in the range 0 to $50 \mathrm{mM}$ at two different $\mathrm{pH}$ values did not lead to any significant change in the value of $k_{\text {obs. }}$.

A comparison between the experimentally determined values and the values from literature (Table 9) shows the influence of the buffer system and of the added co-solvent on the rate constants. 


\begin{tabular}{|c|c|c|c|}
\hline$k_{\mathrm{OH}}\left(\mathrm{M}^{-1} \mathrm{~s}^{-1}\right)$ & $k_{0}\left(s^{-1}\right)$ & reaction conditions & literature \\
\hline 9.5 & $<1.66 \cdot 10^{-3}$ & $\begin{array}{c}\mathrm{T}=25^{\circ} \mathrm{C}, I=1.0 \mathrm{M}(\mathrm{KCl}), 50 \mathrm{mM} \\
\mathrm{H}_{2} \mathrm{O} / \text { triethylamine buffer }\end{array}$ & $3 a$ \\
\hline 23.5 & --- & $\begin{aligned} \mathrm{T}= & 30^{\circ} \mathrm{C}, I=1.0 \mathrm{M}(\mathrm{KCl}), \mathrm{H}_{2} \mathrm{O} / \text { Dioxan } \\
& (1 \%), \mathrm{pH} \text { control by } 1 \mathrm{M} \mathrm{KOH}\end{aligned}$ & $3 b$ \\
\hline 8.1 & $7.28 \cdot 10^{-5}$ & $\begin{array}{c}\mathrm{T}=25^{\circ} \mathrm{C}, I=0, \mathrm{H}_{2} \mathrm{O} / \mathrm{EtOH}(28.5 \%), \\
\text { phosphate buffer }\end{array}$ & $3 \mathrm{c}$ \\
\hline--- & $4.3 \cdot 10^{-7}$ & $\mathrm{~T}=25^{\circ} \mathrm{C}, I=1.0 \mathrm{M}(\mathrm{KCl}), \mathrm{H}_{2} \mathrm{O}$, no buffer & $3 d$ \\
\hline $4.4 ; 8.1 ; 14.7$ & --- & $\begin{array}{c}\mathrm{T}=15,25,35^{\circ} \mathrm{C}, \mathrm{I}=0.1 \mathrm{M}\left(\mathrm{NaNO}_{3}\right), 20 \mathrm{mM} \\
\text { CHES buffer, } \mathrm{H}_{2} \mathrm{O} / \mathrm{CH}_{3} \mathrm{CN}(10 \%)\end{array}$ & $3 e$ \\
\hline 7.84 & $1.12 \cdot 10^{-5}$ & $\begin{array}{c}\mathrm{T}=25{ }^{\circ} \mathrm{C}, I=0.1 \mathrm{M}\left(\mathrm{KNO}_{3}\right), 20 \mathrm{mM} \text { Tris } \\
\text { buffer, } \mathrm{H}_{2} \mathrm{O} / \mathrm{CH}_{3} \mathrm{CN}(10 \%)\end{array}$ & $4 a$ \\
\hline $19.41^{a}$ & $8.16 \cdot 10^{-7}$ & $\begin{array}{c}\mathrm{T}=25^{\circ} \mathrm{C}, I=0.1 \mathrm{M}\left(\mathrm{KNO}_{3}\right), 20 \mathrm{mM} \text { Tris } \\
\text { buffer, } \mathrm{H}_{2} \mathrm{O} / \mathrm{CH}_{3} \mathrm{CN}(10 \%)\end{array}$ & $4 \mathrm{~b}$ \\
\hline 12.41 & $3.67 \cdot 10^{-6}$ & $\begin{array}{l}\mathrm{T}=25^{\circ} \mathrm{C}, I=0.1 \mathrm{M}\left(\mathrm{KNO}_{3}\right), 20 \mathrm{mM} \\
\text { „Goods"-buffer, } \mathrm{H}_{2} \mathrm{O} / \mathrm{CH}_{3} \mathrm{CN}(10 \%)\end{array}$ & $4 c$ \\
\hline 14.8 & --- & $\begin{array}{c}\mathrm{T}=25^{\circ} \mathrm{C}, \mathrm{I}=0.3 \mathrm{M}(\mathrm{NaCl} \text { or } \mathrm{KCl}), 10 \mathrm{mM} \\
\mathrm{H}_{2} \mathrm{O} / \text { triethylamin buffer }\end{array}$ & $4 \mathrm{~d}$ \\
\hline
\end{tabular}

${ }^{a}$ the $k_{\mathrm{OH}}$-value is clearly very different from the other values. The authors have used for their calculations an unusual high value for $\varepsilon_{\mathrm{NP}}\left(20000 \mathrm{~mol}^{-1} \mathrm{~L} \mathrm{~cm}^{-1}, 400 \mathrm{~nm}\right)$ which probably leads to this discrepancy.

Table 9: Literature values for $k_{\mathrm{OH}}$ and $k_{0}$ in the spontaneous hydrolysis of NA.

The spontaneous hydrolysis of NA is generally one order of magnitude faster than any metal catalysed hydrolysis known at present. Therefore the rate of spontaneous hydrolysis of NA has to be determined experimentally for the reaction conditions employed.

\footnotetext{
${ }^{3}$ a) J. F. Kirsch, W. P. Jencks, J. Am. Chem. Soc. 1964, 86, 837-846; b) T. C. Bruice, M. F. Mayahi; J. Am. Chem. Soc. 1960, 82, 3067 - 3071; c) T. C. Bruice, C. L. Schmir, J. Am. Chem. Soc. 1957, 79, 1663-1667; d) W. P. Jencks, M. Gilchrist, J. Am. Chem. Soc. 1968, 90, 2622-2637; e) T. Koike, M. Takamaru, E. Kimura; J. Am. Chem. Soc. 1994, 116, $8443-8449$.

${ }^{4}$ a) S. Zhu, W. Chen, H.-K. Lin, X. Yin, F. Kou, M. Lin, Y. Chen; Polyhedron 1997, 16, 3285 - 3291; b) X.-C. Su, H.-W. Sun, Z.-F. Zhou, H.-K. Lin, L. Chen, S. Zhu, Y.-T. Chen; Polyhedron 2001, 20, 91 - 95; c) Y.-H. Guo, Q.-C. Ge, H. Lin, H.-K. Lin, S.-R. Zhu; Int. J. Chem. Kinet. 2004, 36, 41 - 48; d) W. P. Jencks, J.Carrioulo J. Am. Chem. Soc. 1960, 82, 1778-1786.
} 


\section{4. pH Profiles and species distribution diagrams of the metal complexes in aqueous}

solutions under nitrogen at $25^{\circ} \mathrm{C}$ and $I=0.10$ (TEAP).

In all graphs every second point is represented.

\subsection{Mononuclear complexes}
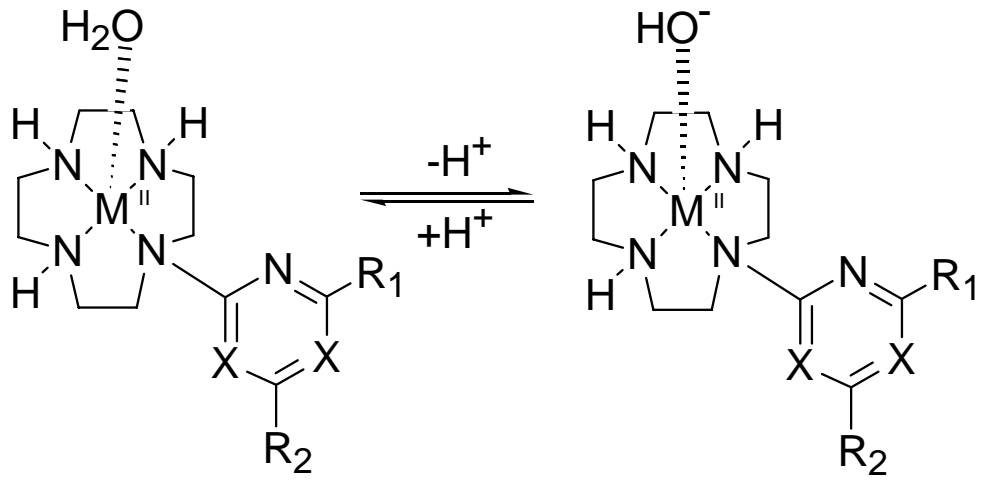

ZnL1 $M=Z n^{\prime \prime}, X=N, R_{1}=R_{2}=O M e$

NiL1 $M=N i^{\prime \prime}, X=N, R_{1}=R_{2}=O M e$

ZnL3 $M=Z n^{\prime \prime}, X=N, R_{1}=O M e, R_{2}=1$-Aza-18-Crown-6

ZnL8 $M=\mathrm{Zn}^{\prime \prime}, \mathrm{X}=\mathrm{CH}, \mathrm{R}_{1}=\mathrm{R}_{2}=\mathrm{H}$

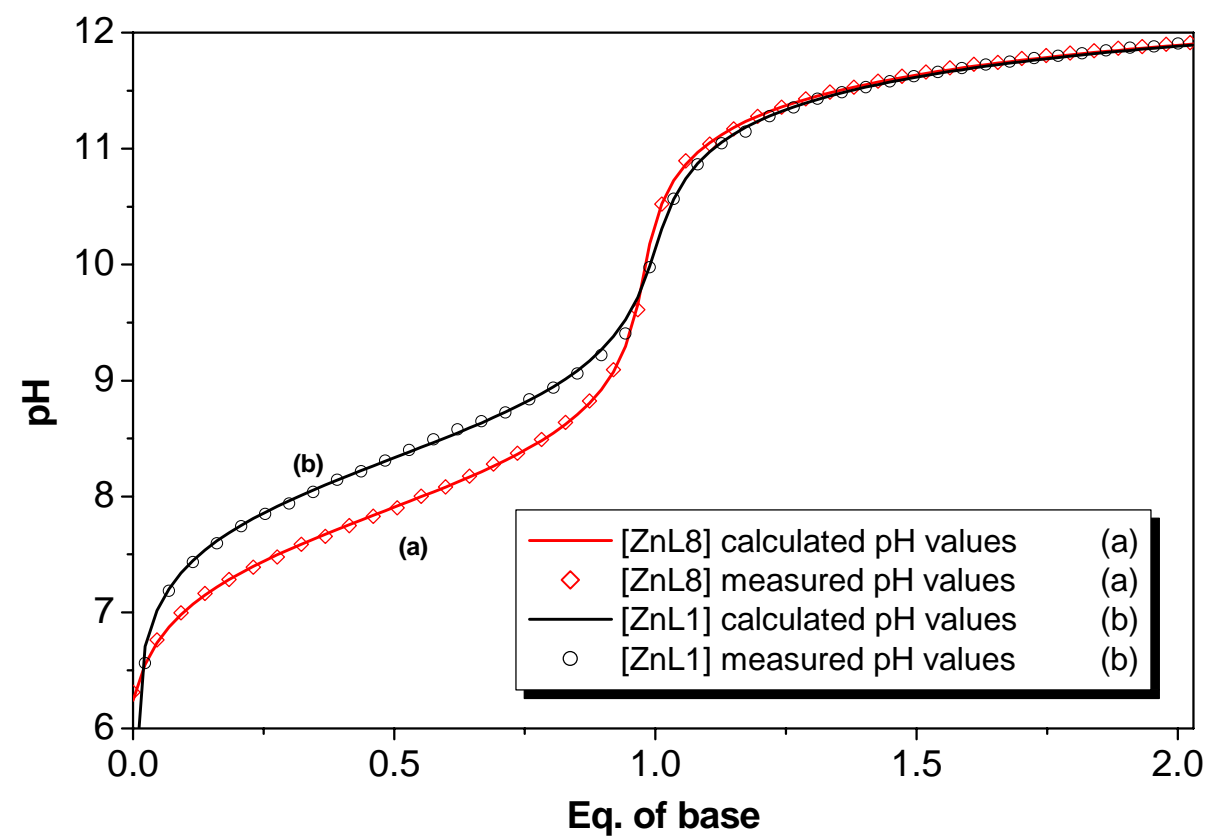

Figure 3. Titration curve for the complexes $[\mathrm{ZnL1}]\left(\mathrm{ClO}_{4}\right)_{2} \cdot \mathrm{H}_{2} \mathrm{O}$ and $[\mathrm{ZnL8}]\left(\mathrm{ClO}_{4}\right)_{2}$ in aqueous solution. The $\mathrm{pH}$ profile of $[\mathrm{ZnL} 3]\left(\mathrm{ClO}_{4}\right)_{2}$ in aqueous solution is similar to that of $[\mathrm{ZnL1}]\left(\mathrm{ClO}_{4}\right)_{2} \cdot \mathrm{H}_{2} \mathrm{O}$ and was omitted for clarity reasons. 


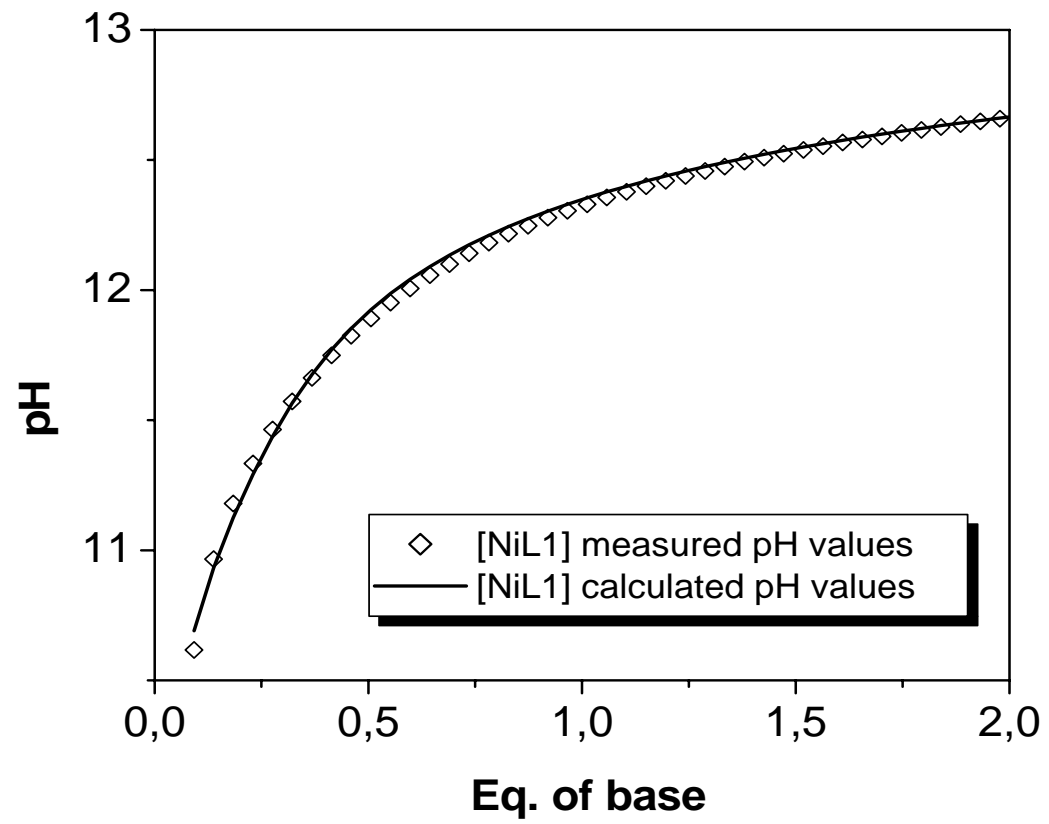

Figure 4. Titration curve for the complex $[\mathrm{NiL1}]\left(\mathrm{ClO}_{4}\right)_{2} \cdot 2 \mathrm{H}_{2} \mathrm{O}$ in aqueous solution

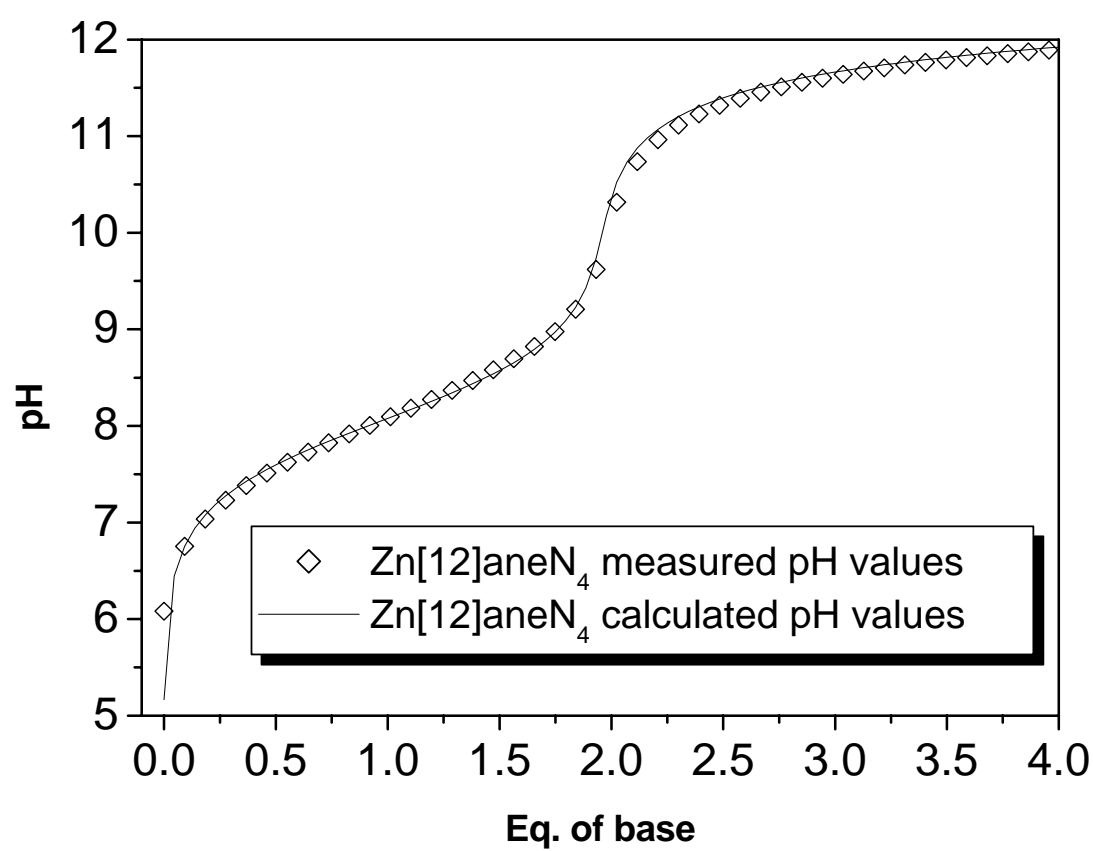

Figure 5. Titration curve for the complex $\mathrm{Zn}[12] \operatorname{aneN}_{4}\left(\mathrm{ClO}_{4}\right)_{2}$ 
With the help of the computer programme Hyperquad a distribution diagram of the de- and protonated species of the metal complexes over the whole $\mathrm{pH}$ range was obtained (Figure 6).

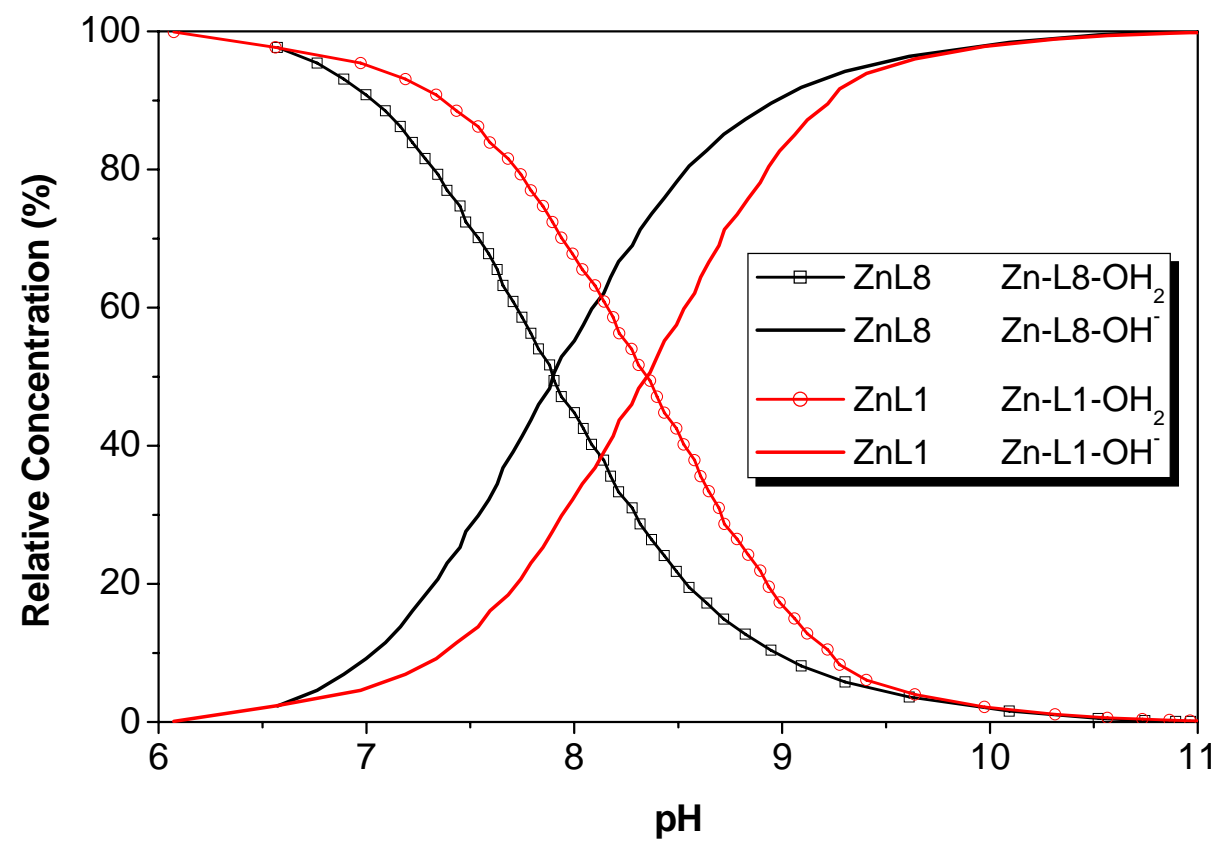

Figure 6. Species distribution diagram of the complexes ZnL1 and ZnL8.

The profile of complex ZnL3 is similar to that of $\mathbf{Z n L 1}$ and was omitted for clarity reasons.

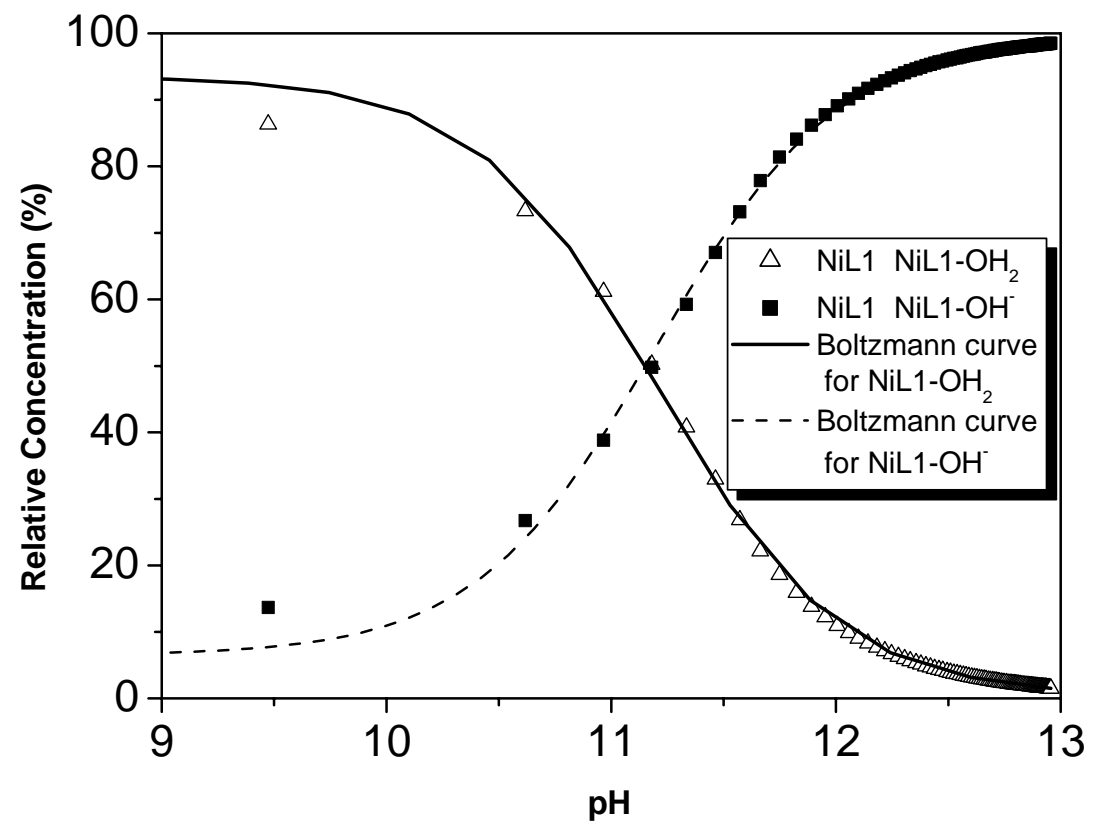

Figure 7. Species distribution diagram of the complex NiL1 


\subsection{Dinuclear complexes}

\subsection{1. pH titration curves}

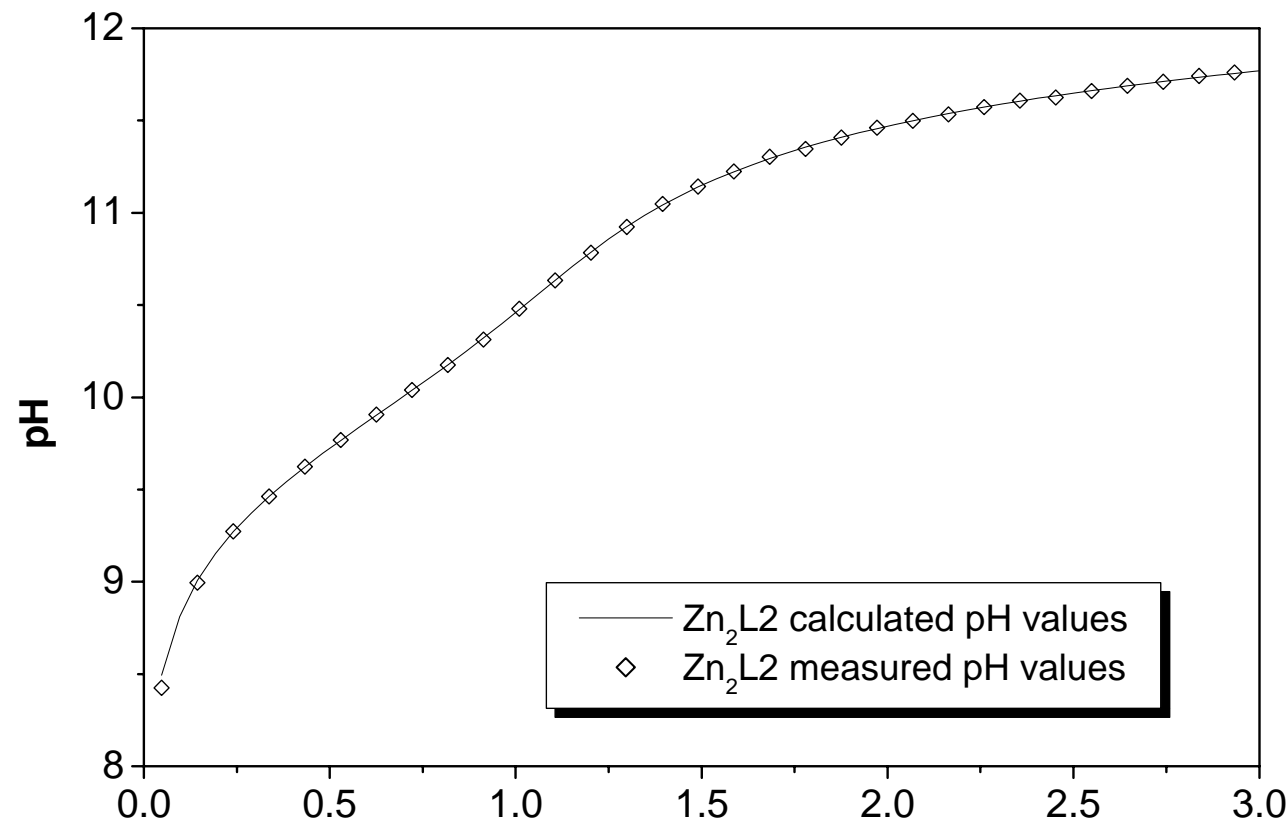

Eq. of base

Figure 8. Titration curve for the complex $\left[\mathrm{Zn}_{2} \mathbf{L 2}\right]\left(\mathrm{ClO}_{4}\right)_{4} \cdot \mathbf{C H}_{3} \mathbf{C N}$ in aqueous solution

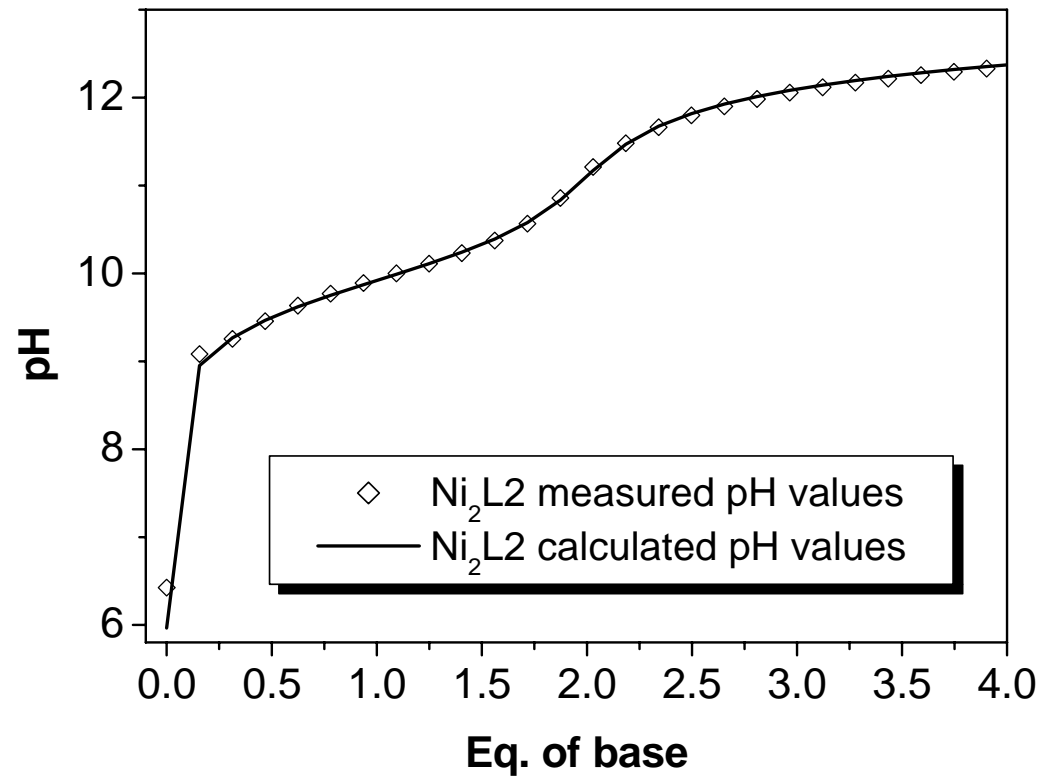

Figure 9. Titration curve for the complex $\left[\mathrm{Ni}_{2} \mathbf{L 2}\right]\left(\mathrm{ClO}_{4}\right)_{4}$ in aqueous solution 


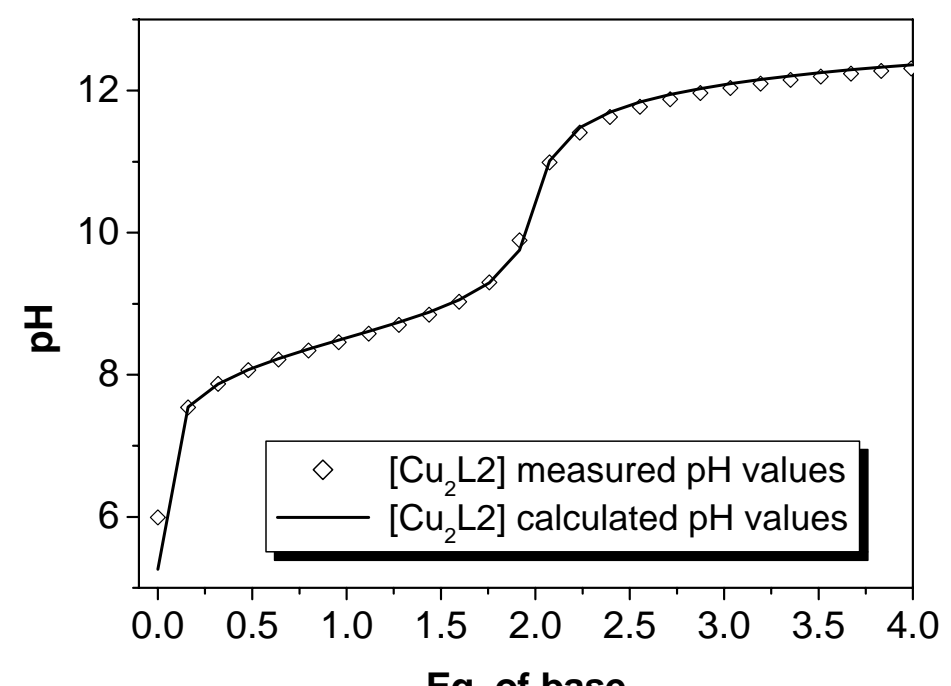

Eq. of base

Figure 10. Titration curve for the complex $\left[\mathrm{Cu}_{2} \mathrm{~L} 2\right]\left(\mathrm{ClO}_{4}\right)_{4} \cdot 2 \mathrm{H}_{2} \mathrm{O}$ in aqueous solution

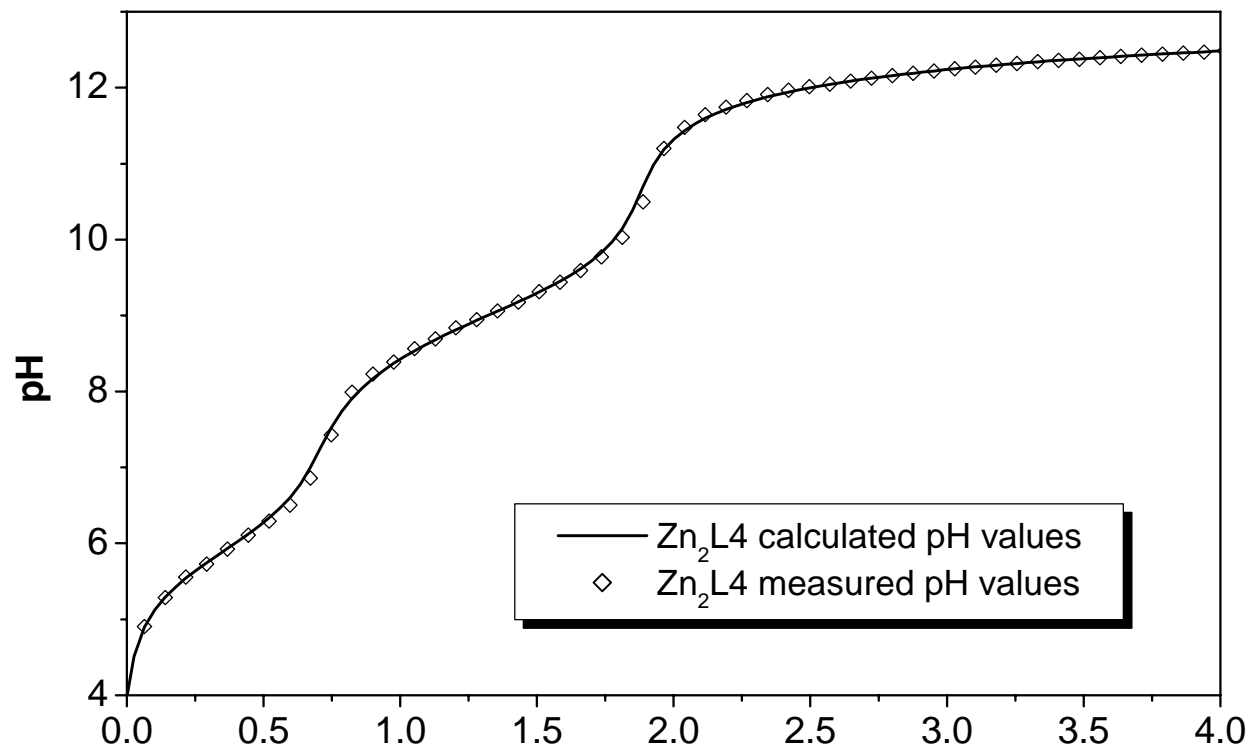

Eq. of base

Figure 11. Titration curve for the complex $\left[\mathbf{Z n}_{2} \mathbf{L} 4\right]\left(\mathbf{C l O}_{4}\right)_{4}$ in aqueous solution $\left(0.5\right.$ eq. $\left.\mathrm{HClO}_{4}\right)$ 


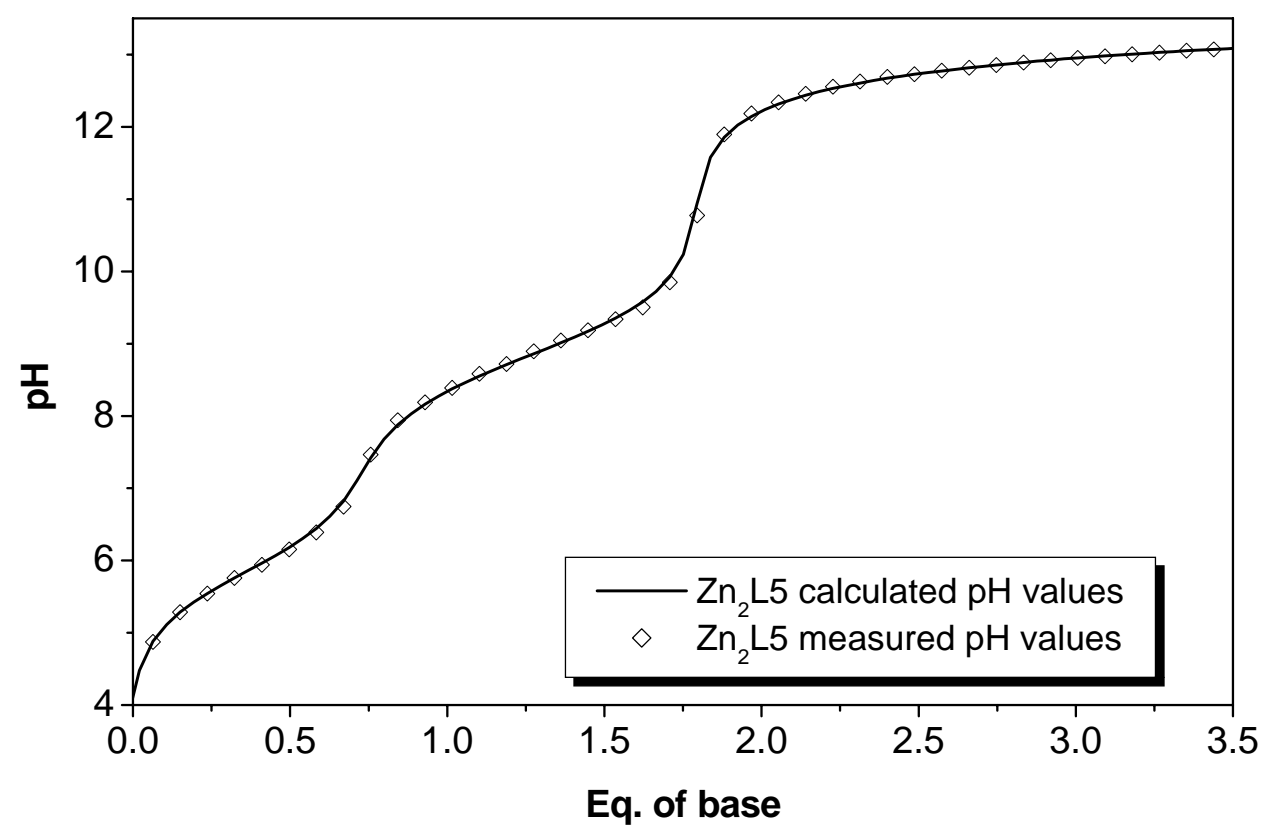

Figure 12. Titration curve for the complex $\left[\mathbf{Z n}_{2} \mathbf{L} \mathbf{L}\right]\left(\mathbf{C l O}_{4}\right)_{4} \cdot \mathbf{H}_{2} \mathbf{O}$ in $\mathrm{MeOH} / \mathrm{H}_{2} \mathrm{O}$ (9:1) solution $\left(0.5\right.$ eq. $\left.\mathrm{HClO}_{4}\right)$

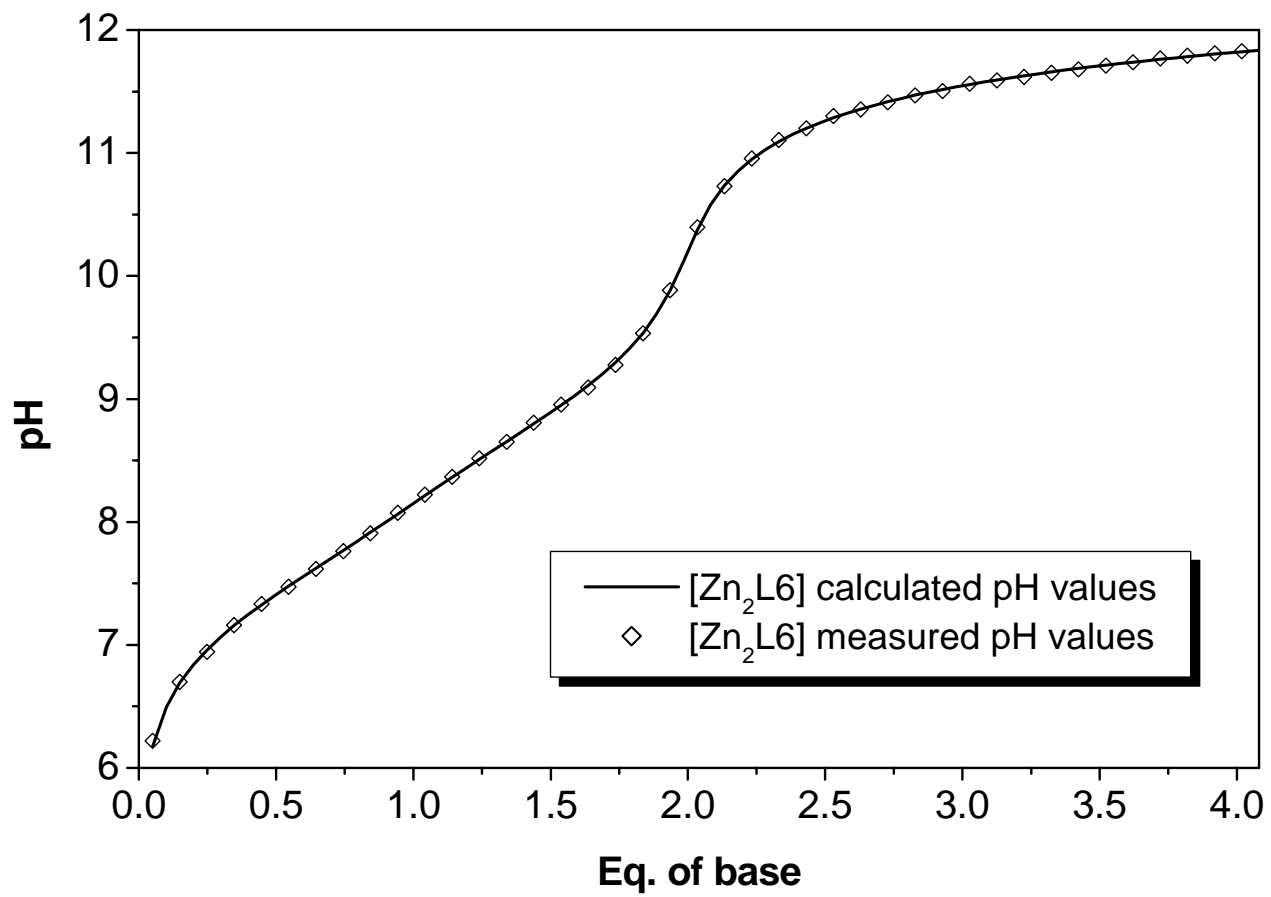

Figure 13. Titration curve for the complex $\left[\mathrm{Zn}_{2} \mathbf{L 6}\right]\left(\mathrm{ClO}_{4}\right)_{4} \cdot \mathrm{H}_{2} \mathrm{O}$ in aqueous solution. 


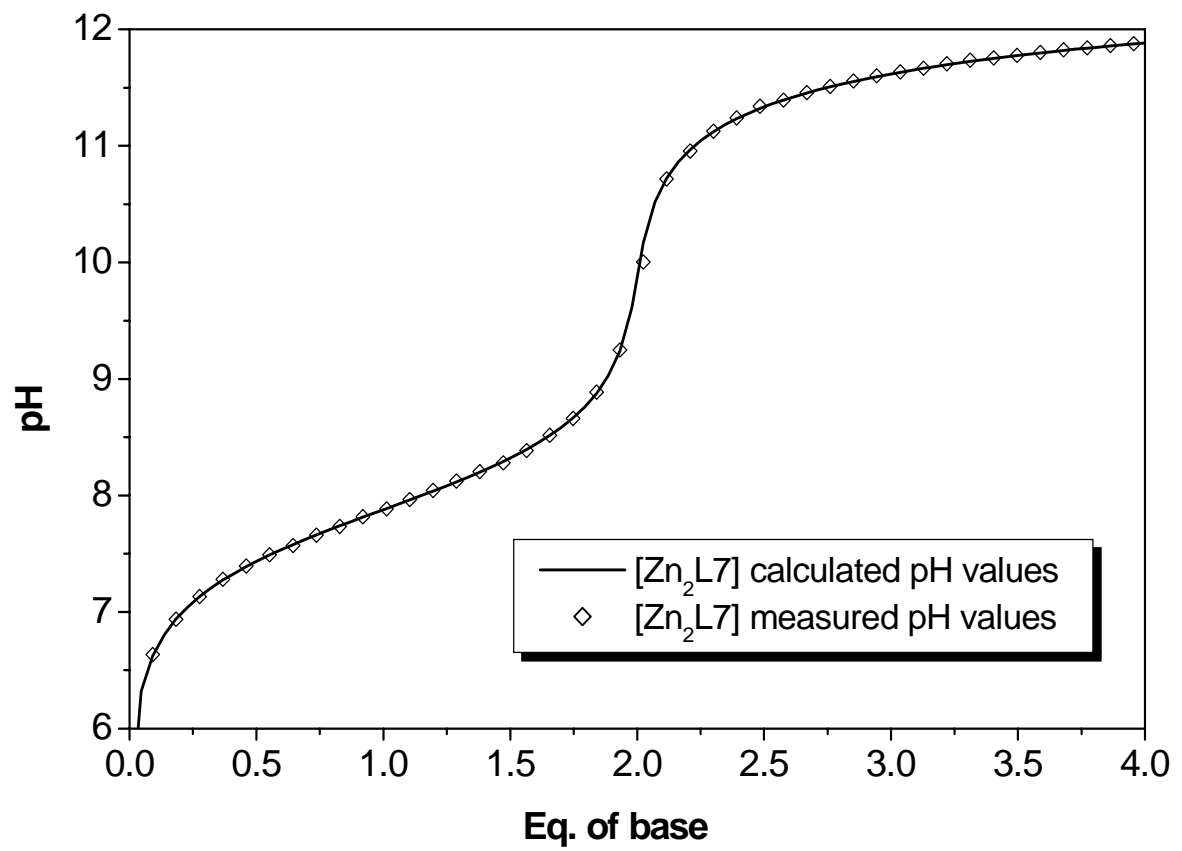

Figure 14. Titration curve for the complex $\left[\mathrm{Zn}_{2} \mathbf{L} 7\right]\left(\mathrm{ClO}_{4}\right)_{4} \cdot \mathbf{C H}_{3} \mathrm{CN}$ in aqueous solution.

\subsubsection{Species distribution diagrams}

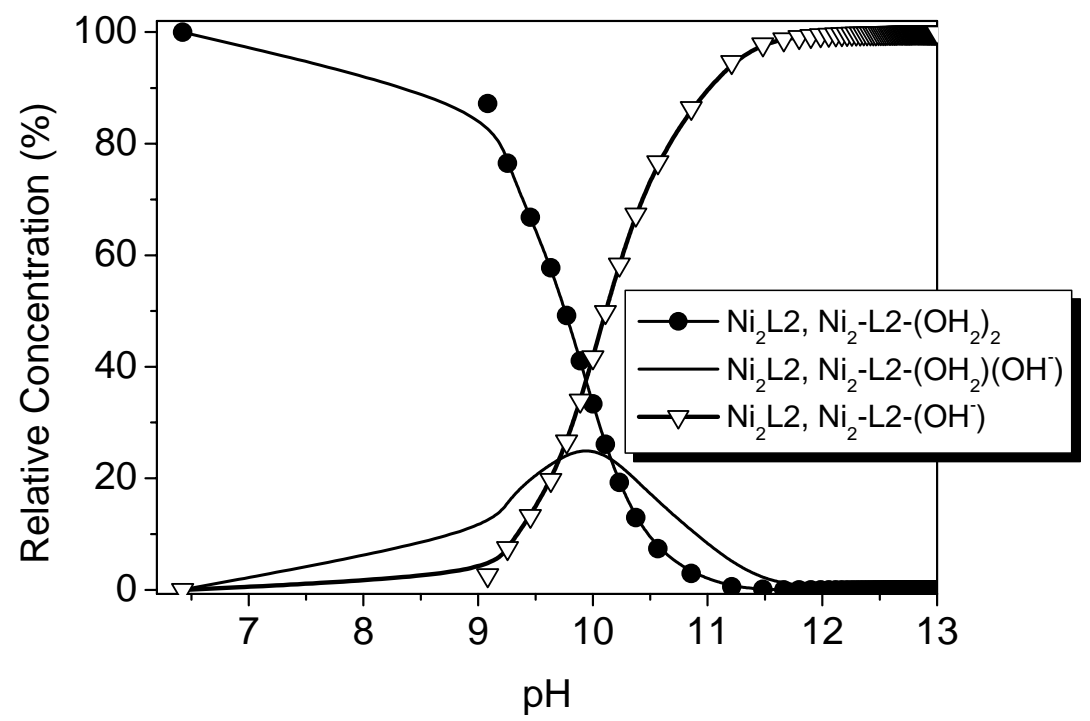

Figure 15. Species distribution diagram for $\left[\mathrm{Ni}_{2} \mathbf{L} 2\right]\left(\mathrm{ClO}_{4}\right)_{4}$ in aqueous solution. 


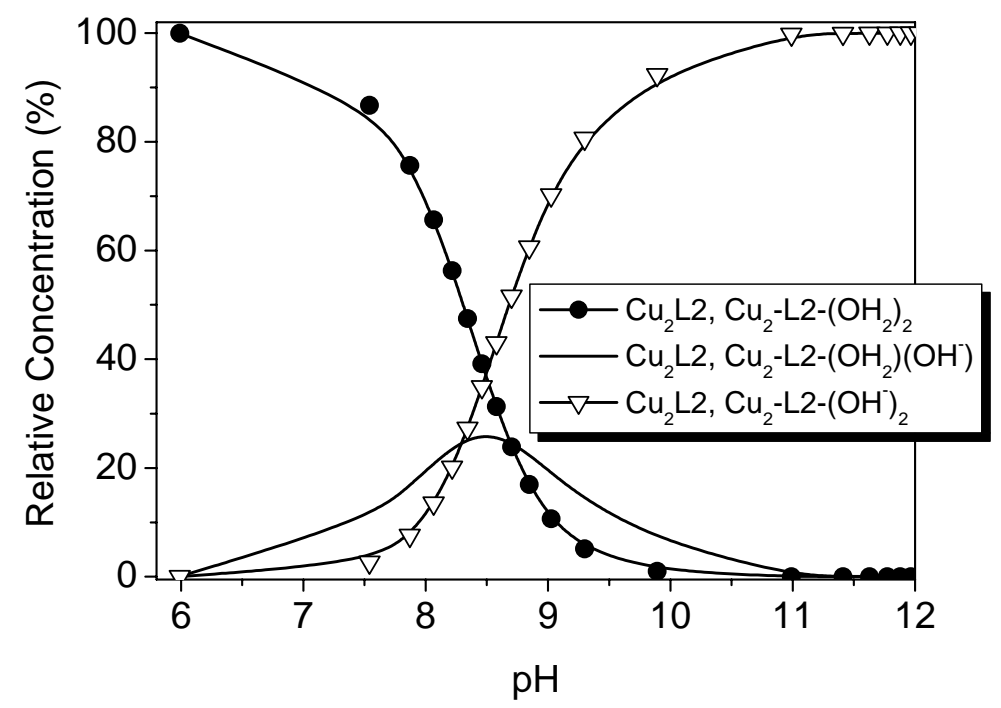

Figure 16. Species distribution diagram for $\left[\mathrm{Cu}_{2} \mathbf{L} 2\right]\left(\mathrm{ClO}_{4}\right)_{4} \cdot 2 \mathrm{H}_{2} \mathrm{O}$ in aqueous solution.

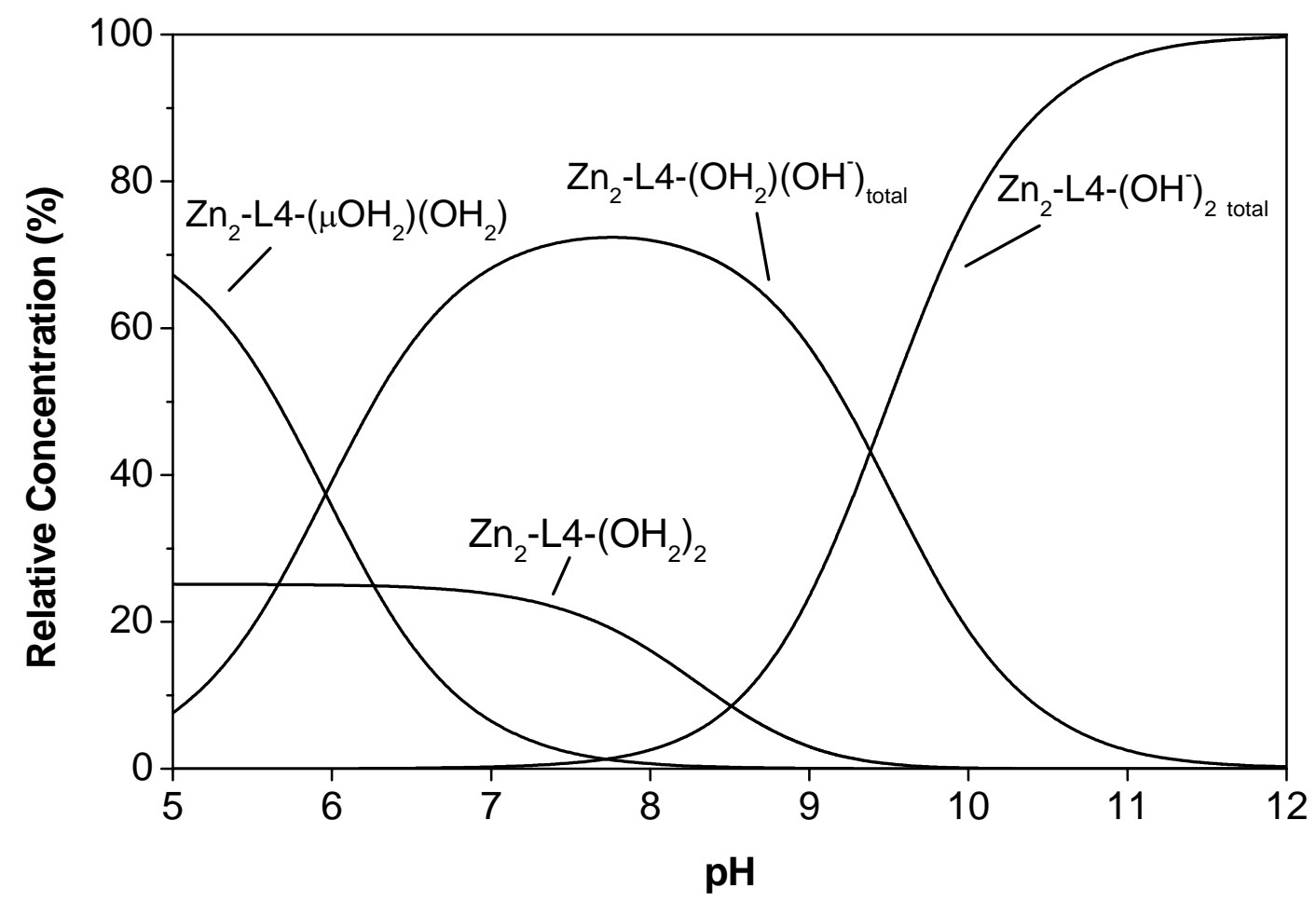

Figure 17. Species distribution diagram for $\left[\mathbf{Z n}_{2} \mathbf{L} 4\right]\left(\mathrm{ClO}_{4}\right)_{4}$ in aqueous solution. 


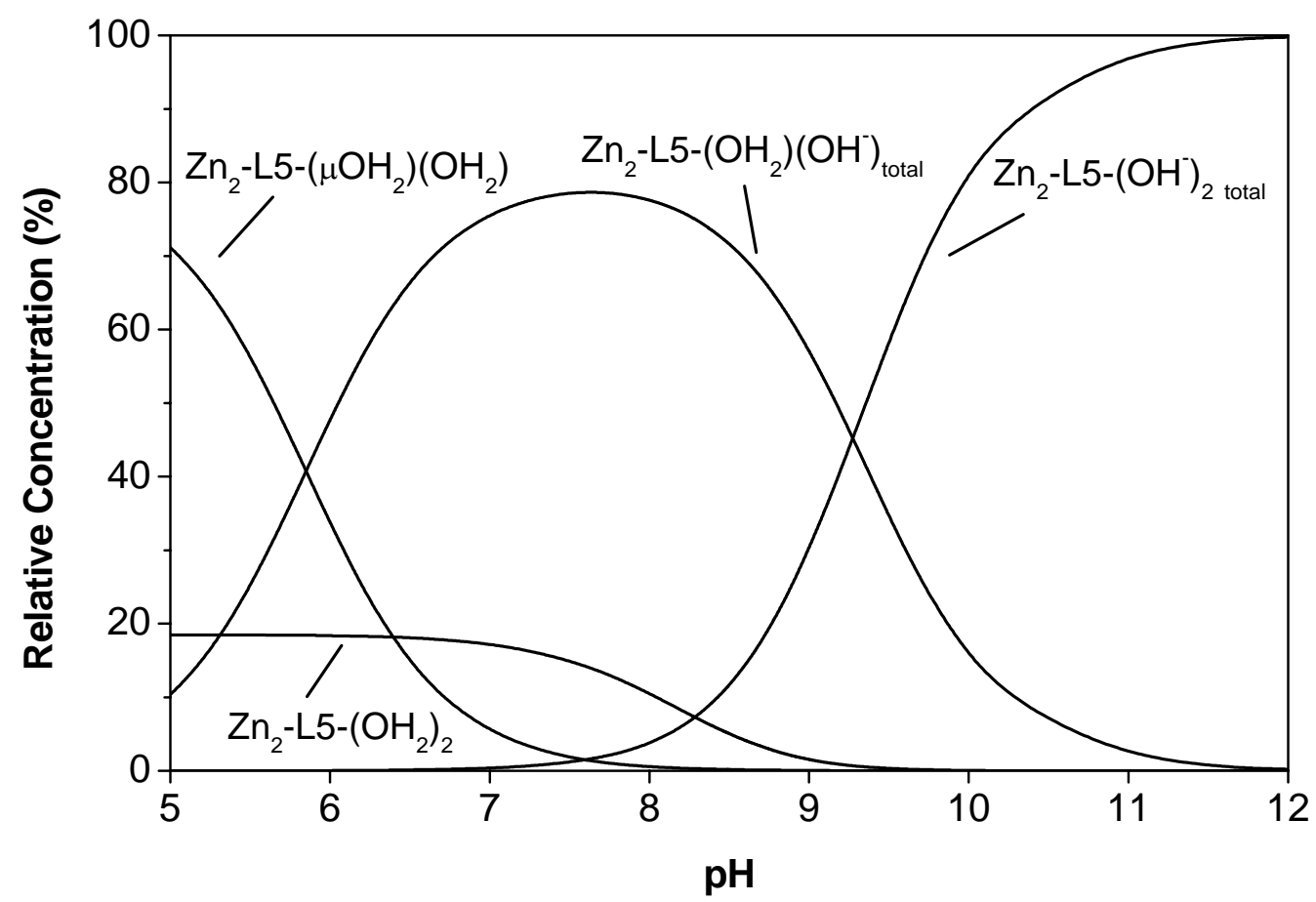

Figure 18. Species distribution diagram for $\left[\mathbf{Z n}_{2} \mathbf{L} 5\right]\left(\mathbf{C l O}_{4}\right)_{\mathbf{4}} \cdot \mathbf{H}_{2} \mathbf{O}$ in $\mathrm{MeOH} / \mathrm{H}_{2} \mathrm{O}$ 9:1.

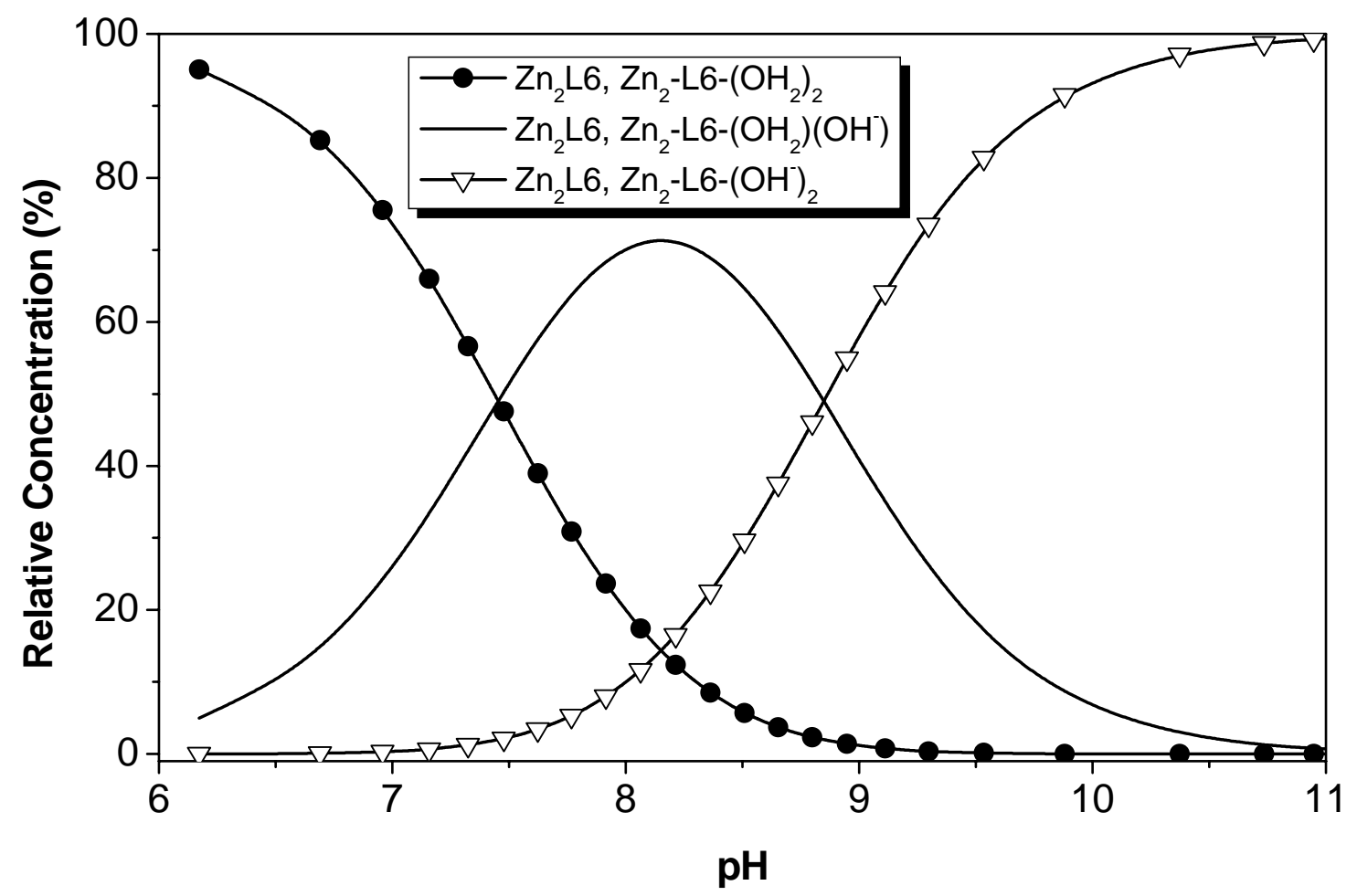

Figure 19. Species distribution diagram for $\left[\mathrm{Zn}_{2} \mathbf{L 6}\right]\left(\mathrm{ClO}_{4}\right)_{4} \cdot \mathrm{H}_{2} \mathrm{O}$ in aqueous solution. 


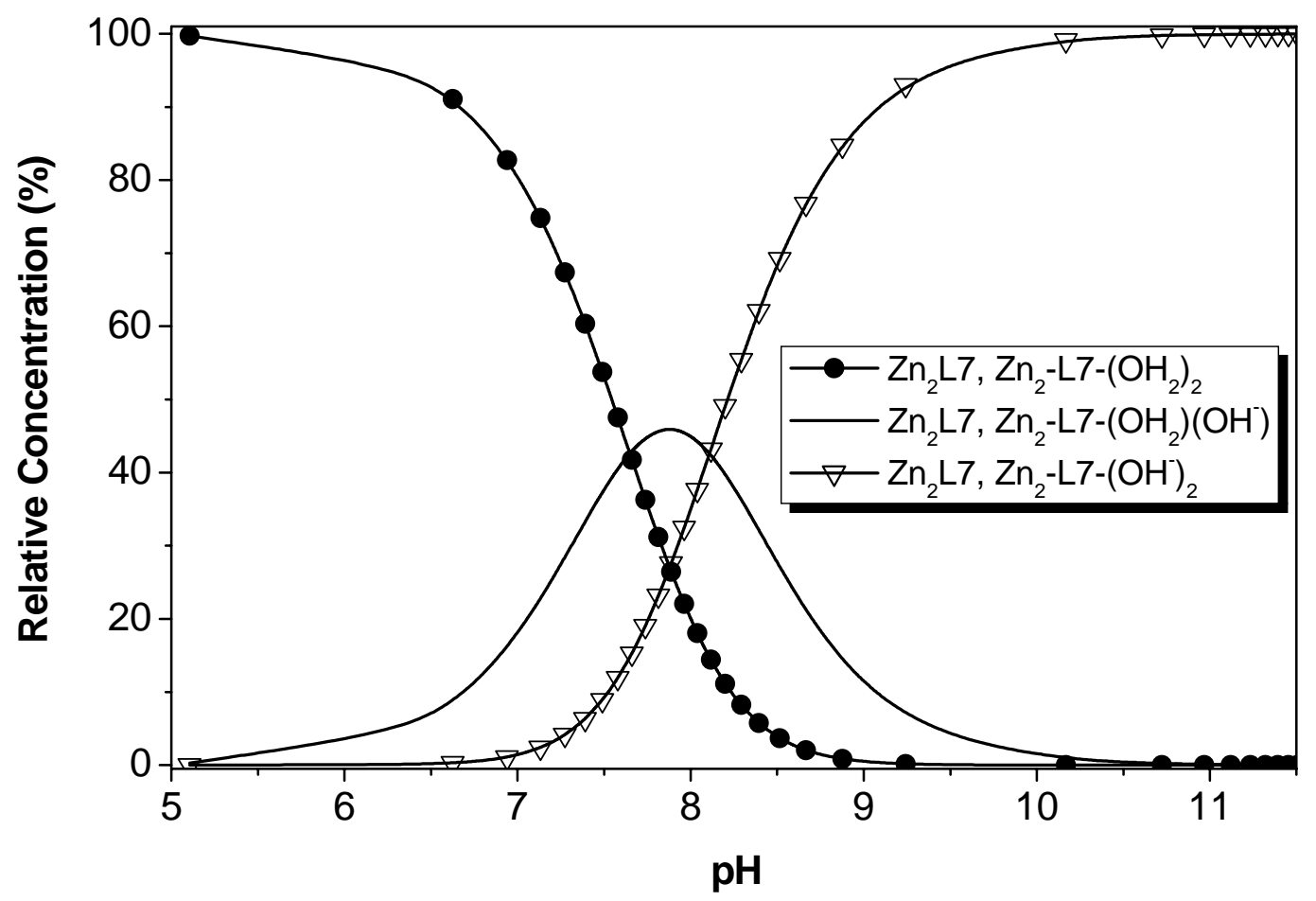

Figure 20. Species distribution diagram for $\left[\mathrm{Zn}_{2} \mathbf{L} 7\right]\left(\mathrm{ClO}_{4}\right)_{4} \cdot \mathrm{CH}_{3} \mathrm{CN}$ in aqueous solution.

5. Plots of $\mathbf{k}_{\mathrm{obs}}$ vs $\mathbf{Z n}$ (II) complex concentration and obtained $\boldsymbol{k}_{\text {cat }}$ values

\subsection{Mononuclear Zn(II) complexes}

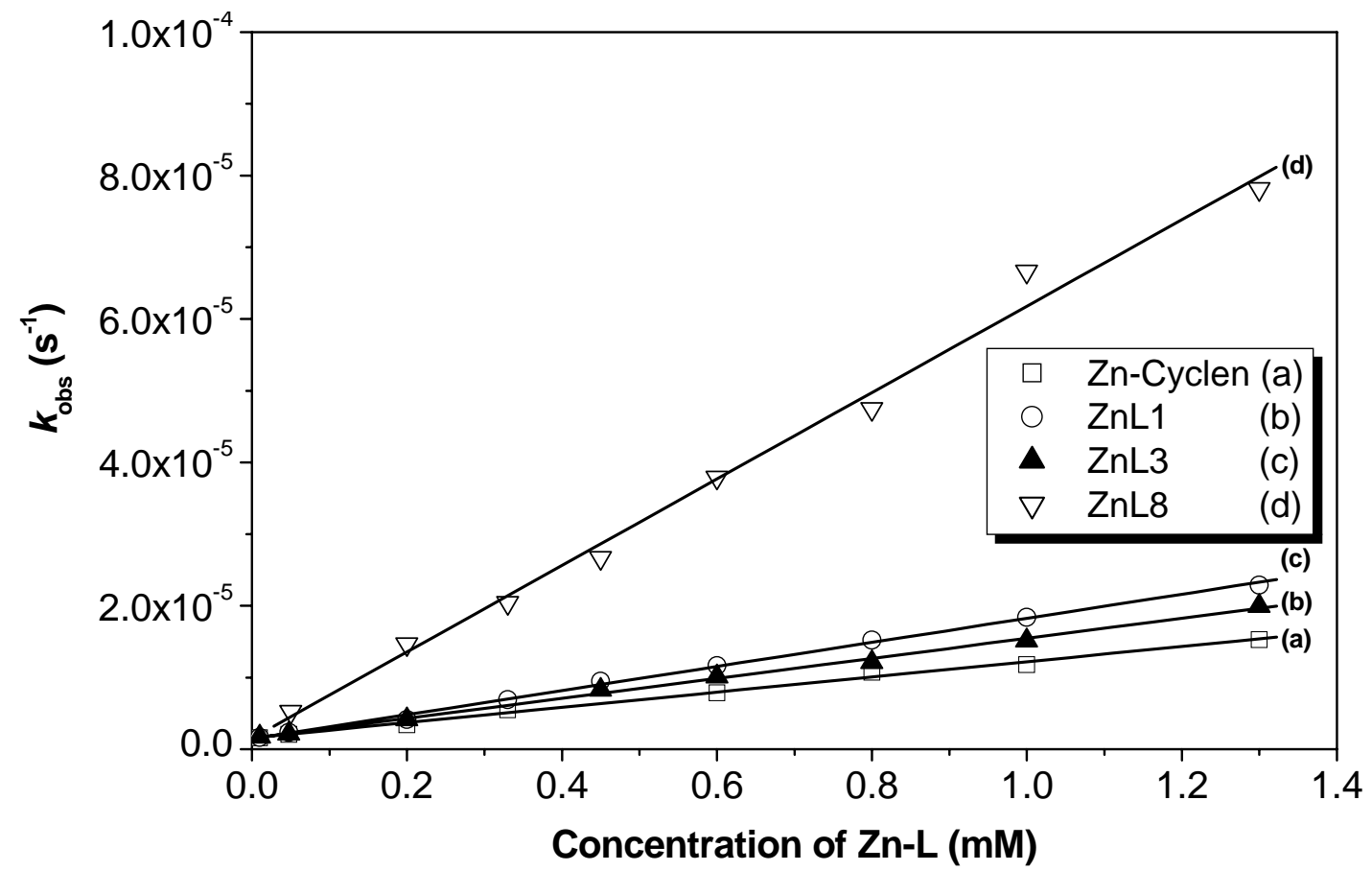

Figure 21: Calculation of the $k_{\text {cat }}$ values for the mononuclear complexes at $\mathrm{pH} 7$. 


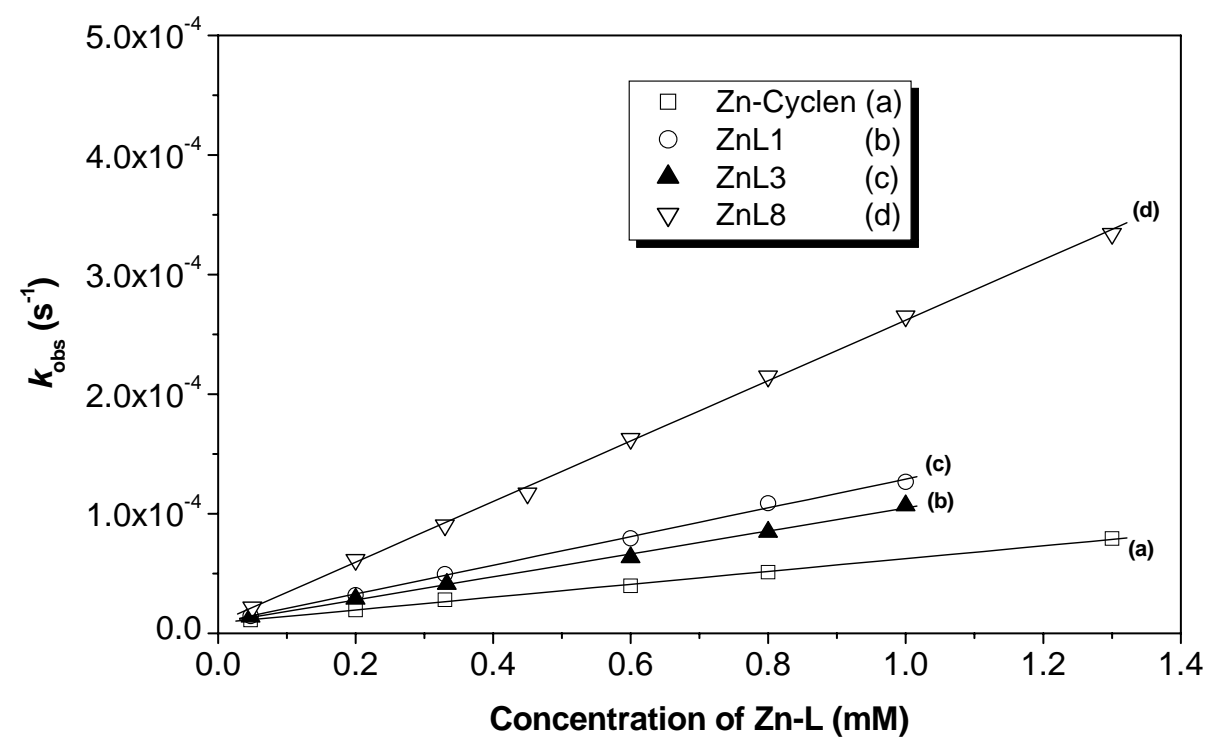

Figure 22: Calculation of the $k_{\text {cat }}$ values for the mononuclear complexes at $\mathrm{pH} 8$.

The value of $k_{\mathrm{OH}}$, the second-order rate constant describes the nucleophilic attack of the $\mathrm{OH}^{-}$ions and is derived from the intercepts of these plots. The obtained values for $k_{\mathrm{OH}}$ of $8.5 \mathrm{M}^{-1} \mathrm{~s}^{-1}$ for $\mathrm{pH}$ 7 and $8.23 \mathrm{M}^{-1} \mathrm{~s}^{-1}$ for $\mathrm{pH} 8$ match the experimentally determined value of $8.16 \mathrm{M}^{-1} \mathrm{~s}^{-1}$. The minor deviation for $\mathrm{pH} 7$ (maximum 11\%) is due to the value of $k_{0}$, the first-order constant describing the solvolysis of the ester due to solvent molecules, which at this $\mathrm{pH}$ value is in the same order of magnitude as $k_{\mathrm{OH}}$.

\begin{tabular}{|c|c|c|}
\hline $\mathrm{pH}$ & $\begin{array}{c}\mathbf{Z n L 8} \\
10^{2} k_{\mathrm{cat}}\left(\mathrm{M}^{-1} \mathrm{~s}^{-1}\right)\end{array}$ & $\begin{array}{c}\mathbf{Z n L 3} \\
10^{2} k_{\mathrm{cat}}\left(\mathrm{M}^{-1} \mathrm{~s}^{-1}\right)\end{array}$ \\
\hline $6.71^{a}$ & 3.4 & 0.52 \\
\hline $7.00^{b}$ & 6.0 & 1.4 \\
\hline $7.43^{b}$ & 13.6 & 3.2 \\
\hline $7.82^{b}$ & 21.5 & 7.4 \\
\hline $8.00^{b}$ & 25.3 & 9.6 \\
\hline $8.52^{b}$ & 33.5 & 17.0 \\
\hline $8.99^{b, c}$ & 36.2 & 23.9 \\
\hline $9.53^{c}$ & 38.1 & 26.1 \\
\hline
\end{tabular}

${ }^{a} 50 \mathrm{mM}$ HEPES buffer, $10 \% \mathrm{CH}_{3} \mathrm{CN}, I=0.1 \mathrm{M}(\mathrm{NaCl}) .{ }^{b} 50 \mathrm{mM}$ TRIS/HCl buffer, $10 \% \mathrm{CH}_{3} \mathrm{CN}, I=0.1 \mathrm{M}(\mathrm{NaCl}){ }^{c}$ CHES buffer $[50 \mathrm{mM}], 10 \% \mathrm{CH}_{3} \mathrm{CN}, I=0.1 \mathrm{M}(\mathrm{NaCl}){ }^{d} \Delta \mathrm{pH}= \pm 0.005, \Delta k_{\text {cat }}= \pm 0.02-0.2 \cdot 10^{-2} \mathrm{M}^{-1} \mathrm{~s}^{-1}$

Table 10: Hydrolysis rate constants $k_{\text {cat }}\left(\mathrm{M}^{-1} \mathrm{~s}^{-1}\right)$ of $\mathrm{ZnL3}$ and $\mathrm{ZnL8}$ for the $\mathrm{pH}$ range 6.5 to 9.6 at $25{ }^{\circ} \mathrm{C}^{d}$ 


\subsection{Dinuclear Zn(II) complexes}

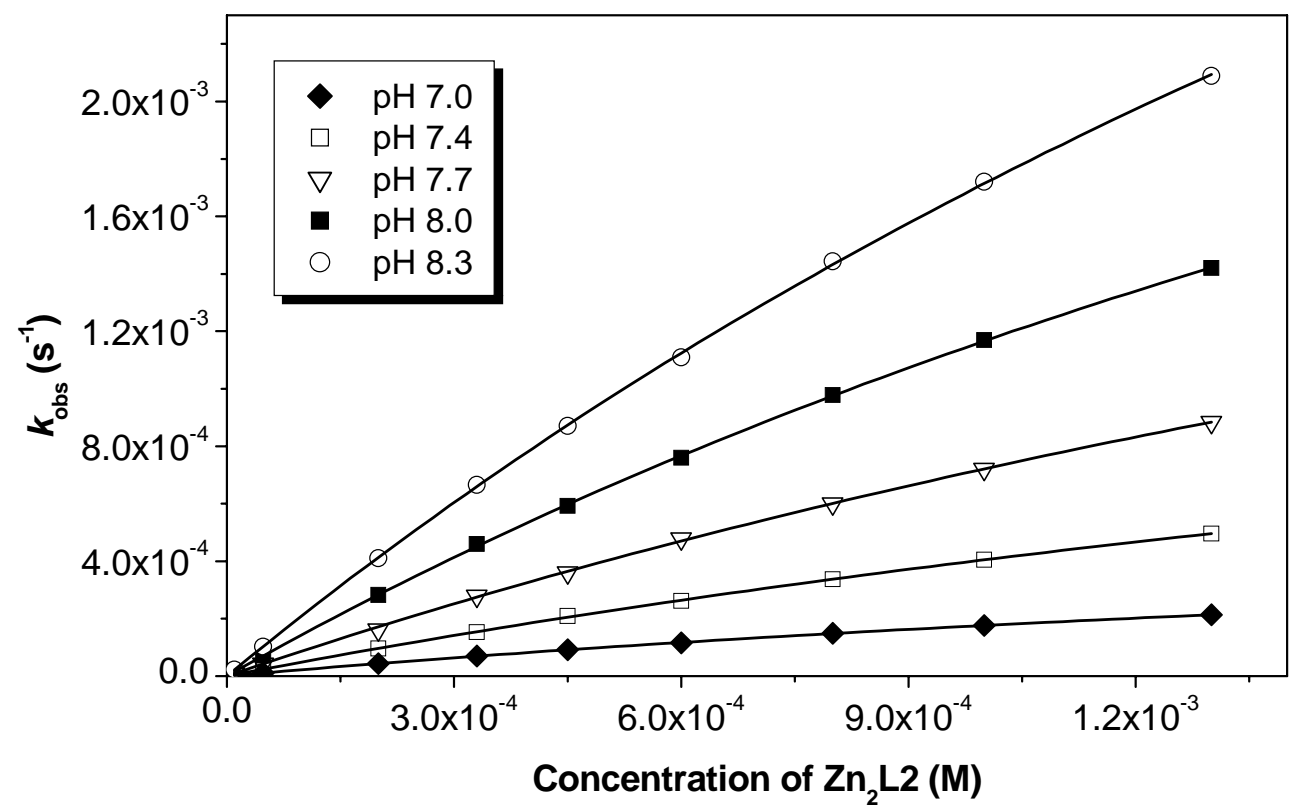

${ }^{a} 50 \mathrm{mM}$ TRIS/HCl buffer, $10 \% \mathrm{CH}_{3} \mathrm{CN}, I=0.1 \mathrm{M}(\mathrm{NaCl}), 25^{\circ} \mathrm{C},[\mathrm{NA}]=1.0-4.0 \cdot 10^{-5} \mathrm{~mol} / \mathrm{L}, \Delta \mathrm{pH}= \pm 0.01$, $\Delta k_{\text {obs }} \pm 0.4-2.7 \%$

Figure 23: Saturation kinetics for $\mathbf{Z} \mathbf{n}_{2} \mathbf{L} 2^{a}$

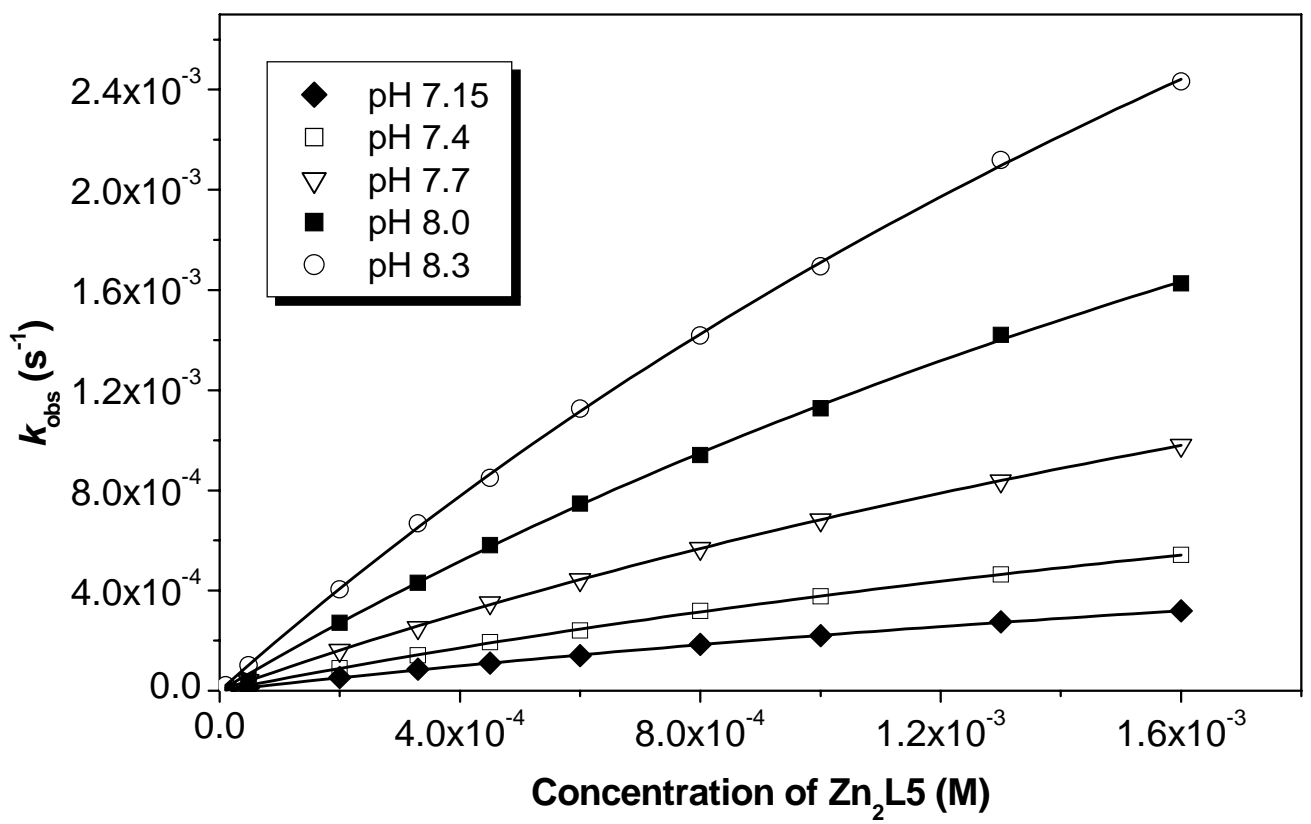

${ }^{a} 50 \mathrm{mM}$ TRIS/HCl buffer, $10 \% \mathrm{CH}_{3} \mathrm{CN}, I=0.1 \mathrm{M}(\mathrm{NaCl}), 25^{\circ} \mathrm{C},[\mathrm{NA}]=1.0-4.0 \cdot 10^{-5} \mathrm{~mol} / \mathrm{L}, \Delta \mathrm{pH}= \pm 0.01$, $\Delta k_{\mathrm{obs}} \pm 0.3-3.1 \%$

Figure 24: Saturation kinetics for $\mathbf{Z} \mathbf{n}_{2} \mathbf{L} 5^{a}$

The saturation kinetics for these complexes is less obvious due to their lower solubility in aqueous solutions. 
6. Results obtained from the saturation kinetic curves of $Z_{2} L 2$, $Z_{2} L 4$ and $Z n_{2} L 5$.

\begin{tabular}{|c|c|c|c|c|}
\hline Complex & pH & $10^{3} k_{\text {cat }}^{\prime}\left(s^{-1}\right)^{a}$ & $10^{3} K_{\mathrm{M}}(\mathrm{M})^{b}$ & $k_{\text {cat }}^{\prime} / K_{M}\left(M^{-1} s^{-1}\right)^{c}$ \\
\hline \multirow[t]{5}{*}{$\mathrm{Zn}_{2} \mathrm{~L} 4$} & 7.0 & $0.81 \pm 0.20$ & $4.3 \pm 0.13$ & 0.19 \\
\hline & 7.4 & $1.9 \pm 0.06$ & $4.5 \pm 0.19$ & 0.42 \\
\hline & 7.7 & $3.3 \pm 0.12$ & $4.4 \pm 0.24$ & 0.73 \\
\hline & 8.0 & $5.3 \pm 0.13$ & $4.4 \pm 0.15$ & 1.22 \\
\hline & 8.3 & $7.4 \pm 0.21$ & $4.1 \pm 0.17$ & 1.80 \\
\hline \multirow[t]{5}{*}{$\mathbf{Z n}_{2} \mathbf{L} 2$} & 7.0 & $0.84 \pm 0.41$ & $3.8 \pm 0.21$ & 0.22 \\
\hline & 7.4 & $2.0 \pm 0.07$ & $3.9 \pm 0.18$ & 0.51 \\
\hline & 7.7 & $3.6 \pm 0.20$ & $4.0 \pm 0.28$ & 0.90 \\
\hline & 8.0 & $5.5 \pm 0.11$ & $3.8 \pm 0.12$ & 1.48 \\
\hline & 8.3 & $8.3 \pm 0.25$ & $3.8 \pm 0.14$ & 2.17 \\
\hline \multirow[t]{5}{*}{$\mathrm{Zn}_{2} \mathbf{L} 5$} & 7.15 & $1.2 \pm 0.06$ & $4.5 \pm 0.27$ & 0.27 \\
\hline & 7.4 & $2.0 \pm 0.08$ & $4.2 \pm 0.21$ & 0.47 \\
\hline & 7.7 & $3.6 \pm 0.10$ & $4.2 \pm 0.15$ & 0.85 \\
\hline & 8.0 & $5.8 \pm 0.26$ & $4.1 \pm 0.23$ & 1.42 \\
\hline & 8.3 & $8.5 \pm 0.35$ & $4.0 \pm 0.21$ & 2.14 \\
\hline
\end{tabular}

${ }^{a} \Delta k_{\text {cat }}^{\prime}= \pm 2.4-4.9 \%{ }^{b} \Delta K_{\mathrm{M}}= \pm 3.1-6.9 \%{ }^{c}{ }^{c} k^{\prime}{ }_{\text {cat }} / K_{\mathrm{M}}=k_{\text {cat }}$ (bimolecular), $\Delta k_{\text {cat }}= \pm 3.9-8.2 \%{ }^{d}$ The regression coefficients $\mathrm{R}^{2}>0.9997$ were obtained.

Table 11: Results obtained from the non-linear fit of equation (6) ${ }^{d}$.

The higher error margins compared to the mononuclear $\mathrm{Zn}$ (II) complexes are due to the nonlinear fit, which requires an extrapolation over a higher concentration range. 
7. Second-order rate constants $k_{\text {cat 1,2 }}\left(M^{-1} s^{-1}\right)$ for $Z_{2} L 7$ and $Z_{2} L 6$.

\begin{tabular}{|c|c|c|c|c|c|}
\hline $\mathbf{p H}$ & $\boldsymbol{k}_{\text {cat 1,2 }}\left(\mathbf{M}^{-1} \mathbf{s}^{-\mathbf{1}}\right)$ & $\mathbf{p H}$ & $\boldsymbol{k}_{\text {cat } 1,2}\left(\mathbf{M}^{-1} \mathbf{s}^{-1}\right)$ & $\mathbf{p H}$ & $\boldsymbol{k}_{\text {cat 1,2 }}\left(\mathbf{M}^{-1} \mathbf{s}^{-\mathbf{1}}\right)$ \\
\hline $6.22^{a}$ & 0.0149 & $7.38^{c}$ & 0.1813 & $8.76^{c}$ & 0.7019 \\
\hline $6.54^{a}$ & 0.0312 & $7.59^{c}$ & 0.2671 & $8.76^{d}$ & 0.7053 \\
\hline $6.72^{a}$ & 0.0461 & $7.71^{c}$ & 0.3221 & $9.00^{c}$ & 0.7340 \\
\hline $6.72^{b}$ & 0.0456 & $7.81^{c}$ & 0.3788 & $9.15^{d}$ & 0.7516 \\
\hline $6.83^{b}$ & 0.0551 & $8.00^{c}$ & 0.4481 & $9.34^{d}$ & 0.7701 \\
\hline $6.92^{b}$ & 0.0724 & $8.12^{c}$ & 0.5048 & $9.57^{d}$ & 0.7786 \\
\hline $7.11^{b}$ & 0.1100 & $8.20^{c}$ & 0.5404 & $9.79^{d}$ & 0.7832 \\
\hline $7.11^{c}$ & 0.1087 & $8.34^{c}$ & 0.6022 & $9.99^{d}$ & 0.7867 \\
\hline $7.31^{c}$ & 0.1559 & $8.52^{c}$ & 0.6453 & $10.18^{d}$ & 0.7866 \\
\hline
\end{tabular}

${ }^{a}$ BIS/TRIS buffer [ $[50 \mathrm{mM}], 10 \% \mathrm{CH}_{3} \mathrm{CN}, I=0.1 \mathrm{M}(\mathrm{NaCl}), 25^{\circ} \mathrm{C} .{ }^{b} \mathrm{HEPES}$ buffer $[50 \mathrm{mM}], 10 \% \mathrm{CH}_{3} \mathrm{CN}, I=0.1$ $\mathrm{M}(\mathrm{NaCl}), 25^{\circ} \mathrm{C} .{ }^{c} \mathrm{TRIS} / \mathrm{HCl}$ buffer $[50 \mathrm{mM}], 10 \% \mathrm{CH}_{3} \mathrm{CN}, \mathrm{I}=0.1 \mathrm{M}(\mathrm{NaCl}), 2{ }^{\circ} \mathrm{C} .{ }^{d} \mathrm{CHES}$ buffer $[50 \mathrm{mM}], 10 \%$ $\mathrm{CH}_{3} \mathrm{CN}, I=0.1 \mathrm{M}(\mathrm{NaCl}), 25^{\circ} \mathrm{C}$.

$\Delta \mathrm{pH}= \pm 0.005, \Delta k_{\text {cat } 1,2}= \pm 0.05-0.3 \cdot 10^{-2} \mathrm{M}^{-1} \mathrm{~s}^{-1}, \Delta k_{\mathrm{obs}} 1,2= \pm 0.5-3.8 \%$

Table 12: $k_{\text {cat } 1,2}$ values for $\mathbf{Z n}_{2} \mathbf{L} 7$ for the pH range 6.2 to 10.2 .

\begin{tabular}{|c|c|c|c|c|c|}
\hline $\mathrm{pH}$ & $k_{\text {cat } 1,2}\left(\mathrm{M}^{-1} \mathrm{~s}^{-1}\right)$ & $\mathrm{pH}$ & $k_{\text {cat } 1,2}\left(\mathrm{M}^{-1} \mathrm{~s}^{-1}\right)$ & $\mathrm{pH}$ & $k_{\text {cat } 1,2}\left(\mathrm{M}^{-1} \mathrm{~s}^{-1}\right)$ \\
\hline $6.29^{a, e}$ & 0.0370 & $7.21^{c}$ & 0.2193 & $8.71^{d}$ & 0.6175 \\
\hline $6.58^{a, e}$ & 0.0699 & $7.49^{c}$ & 0.3191 & $9.01^{c}$ & 0.6580 \\
\hline $6.91^{a, e}$ & 0.1273 & $7.81^{c}$ & 0.4112 & $9.32^{d}$ & 0.6746 \\
\hline $6.91^{b, e}$ & 0.1283 & $8.12^{c}$ & 0.4979 & $9.59^{d}$ & 0.6999 \\
\hline $7.03^{b, e}$ & 0.1590 & $8.40^{c}$ & 0.5601 & $9.91^{d}$ & 0.7017 \\
\hline $7.03^{c, e}$ & 0.1528 & $8.71^{c}$ & 0.6190 & $10.18^{d}$ & 0.7097 \\
\hline
\end{tabular}

${ }^{a}$ BIS/TRIS buffer [ $\left.50 \mathrm{mM}\right], 10 \% \mathrm{CH}_{3} \mathrm{CN}, I=0.1 \mathrm{M}(\mathrm{NaCl}), 25^{\circ} \mathrm{C} .{ }^{b} \mathrm{HEPES}$ buffer $[50 \mathrm{mM}], 10 \% \mathrm{CH}_{3} \mathrm{CN}, I=0.1$ $\mathrm{M}(\mathrm{NaCl}), 25^{\circ} \mathrm{C} .{ }^{c} \mathrm{TRIS} / \mathrm{HCl}$ buffer $[50 \mathrm{mM}], 10 \% \mathrm{CH}_{3} \mathrm{CN}, I=0.1 \mathrm{M}(\mathrm{NaCl}), 25{ }^{\circ} \mathrm{C} .{ }^{d} \mathrm{CHES}$ buffer $[50 \mathrm{mM}], 10 \%$ $\mathrm{CH}_{3} \mathrm{CN}, I=0.1 \mathrm{M}(\mathrm{NaCl}), 25^{\circ} \mathrm{C}$. ${ }^{\mathrm{e}}$ The $k_{\text {cat } 1,2}$ value corresponds to the $k_{\text {cat } 1}$ value, as the percentage of dihydroxy species present in solution is less than $0.5 \%$ for these $\mathrm{pH}$ values.

$\Delta \mathrm{pH}= \pm 0.005, \Delta k_{\text {cat } 1,2}= \pm 0.05-0.35 \cdot 10^{-2} \mathrm{M}^{-1} \mathrm{~s}^{-1}, \Delta k_{\mathrm{obs}} 1,2= \pm 0.6-3.6 \%$

Table 13: $k_{\text {cat } 1,2}$ values for $\mathbf{Z n}_{2} \mathbf{L} \mathbf{6}$ for the $\mathrm{pH}$ range 6.2 to 10.2. 
8. Graphical representation of the relationship between measured $\boldsymbol{k}_{\mathrm{cat}}{ }_{1,2}$, the speciesdistribution diagram and the calculated $k_{\text {cat } 1}$ and $k_{\text {cat } 2}$ for $Z_{2} L 7$ and $Z_{2} L 6$.

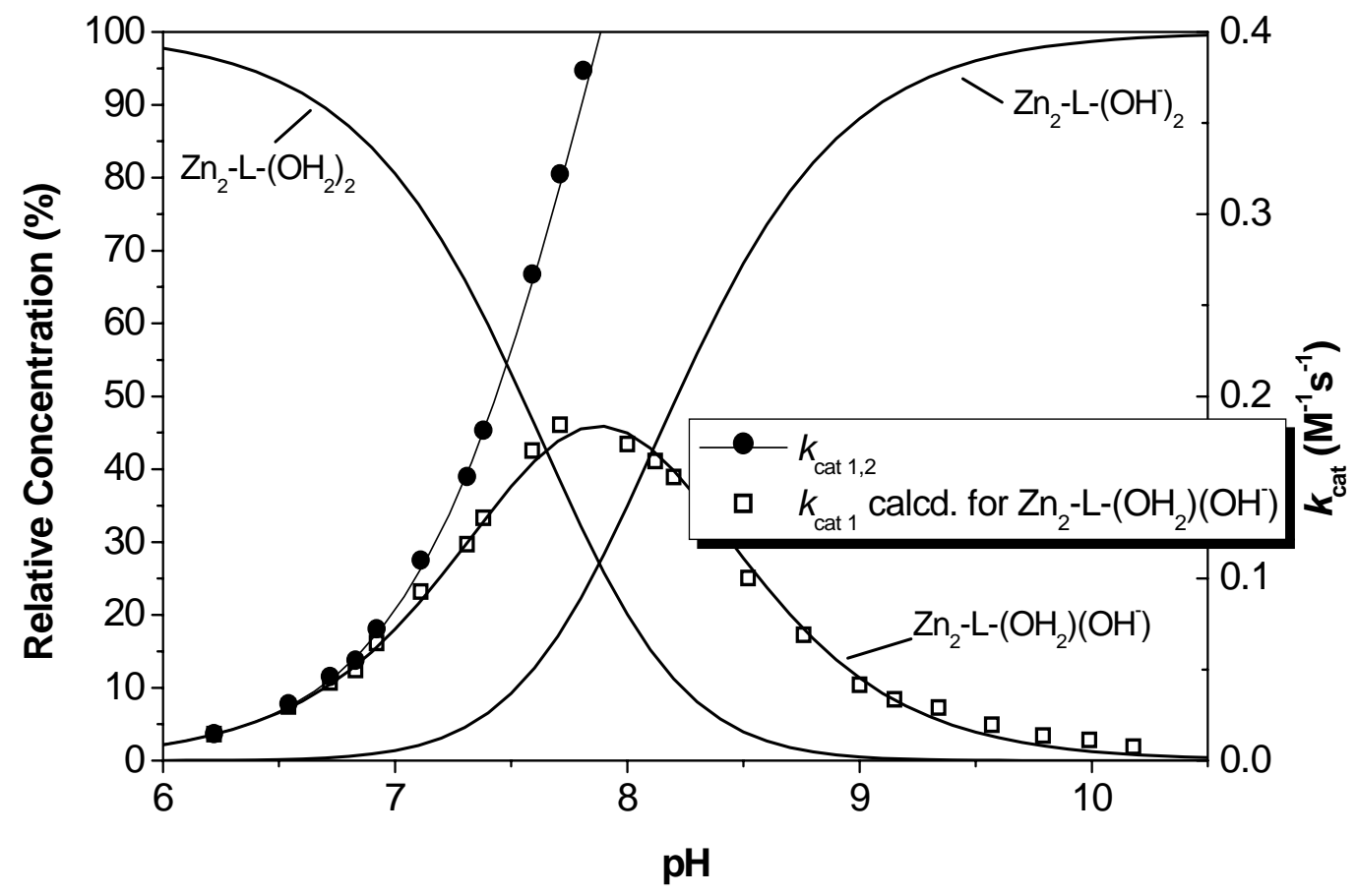

Figure 25: Species-distribution diagram of $\mathbf{Z} \mathbf{n}_{2} \mathbf{L} 7$ with measured $k_{\text {cat } 1,2}$ values and calculated $k_{\text {cat } 1 \text { values. }}$

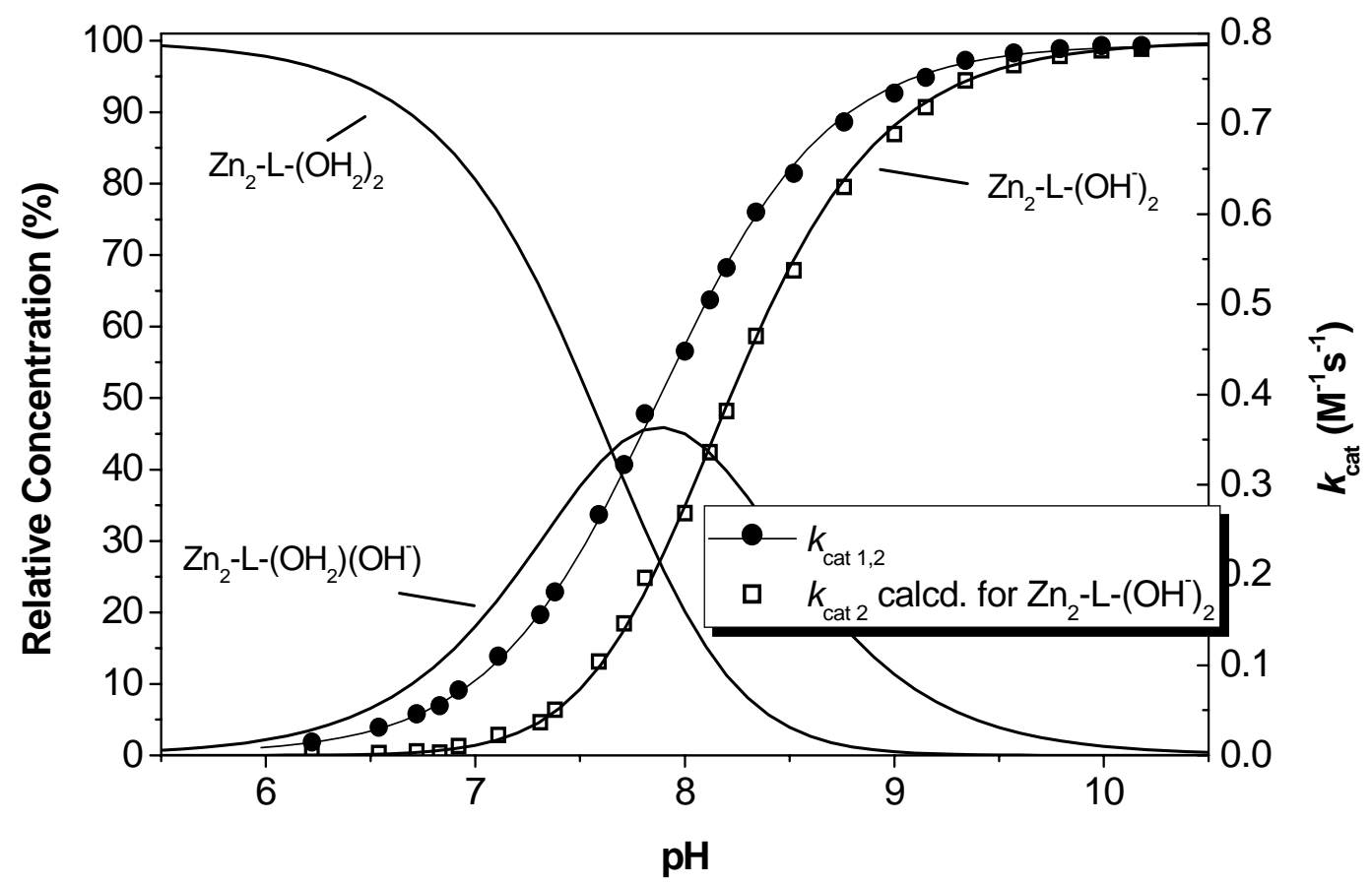

Figure 26: Species-distribution diagram of $\mathbf{Z} \mathbf{n}_{2} \mathbf{L} 7$ with measured $k_{\text {cat } 1,2}$ values and calculated $k_{\text {cat } 2}$ values. 


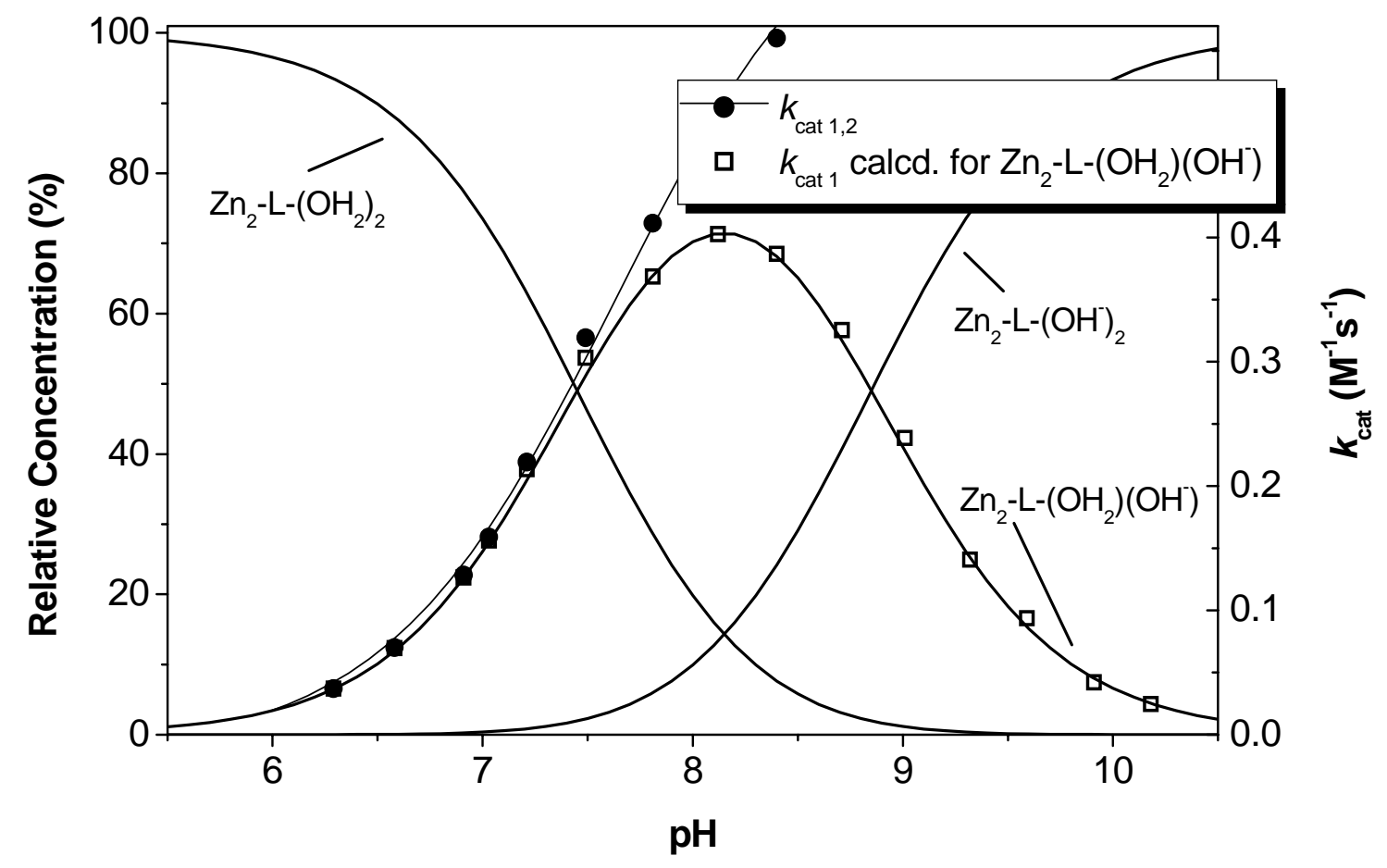

Figure 27: Species-distribution diagram of $\mathbf{Z n}_{\mathbf{2}} \mathbf{L 6}$ with measured $k_{\mathrm{cat}}$ 1,2 values and calculated $k_{\text {cat } 1}$ values.

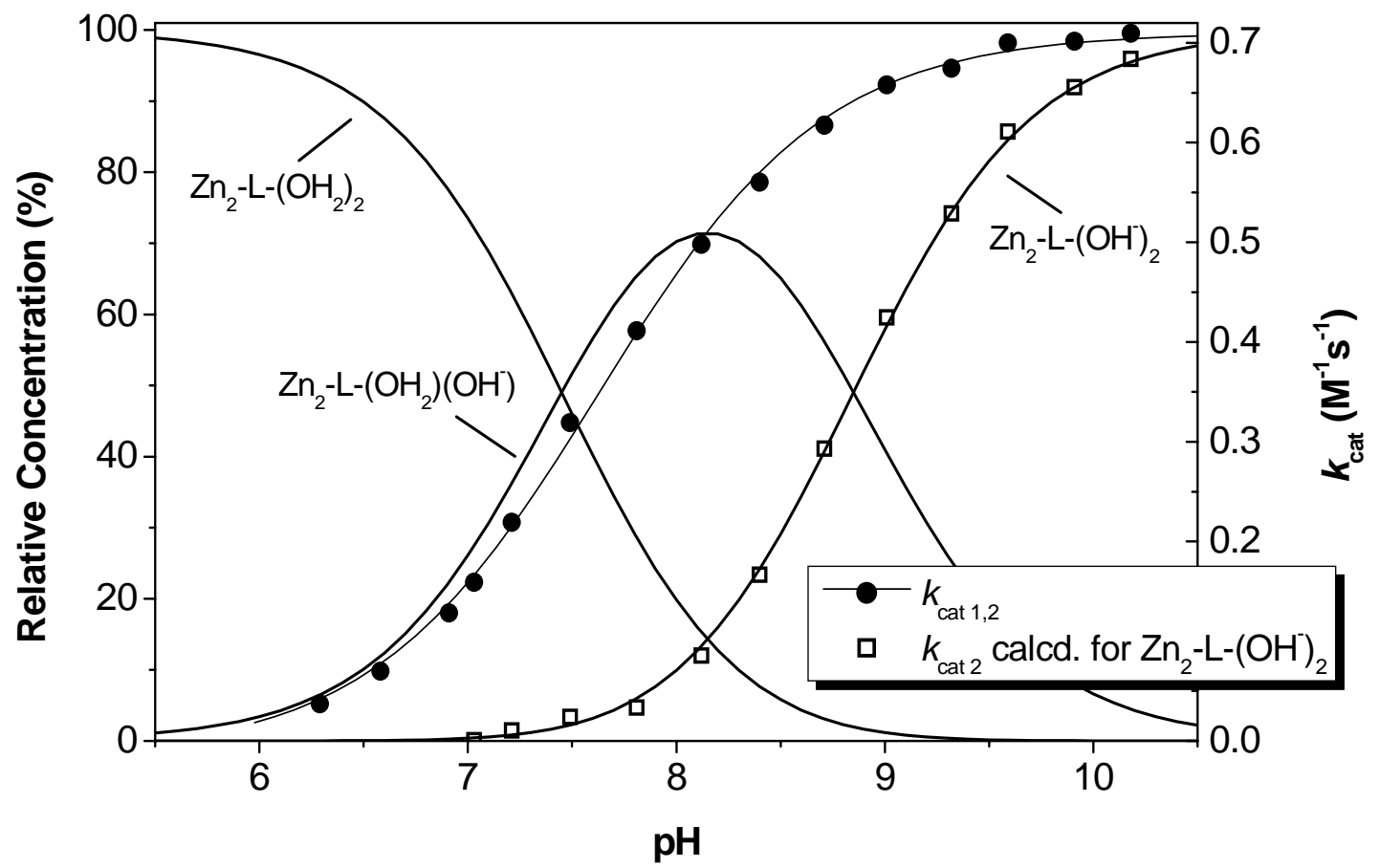

Figure 28: Species-distribution diagram of $\mathbf{Z} \mathbf{n}_{2} \mathbf{L 6}$ with measured $k_{\text {cat } 1,2}$ values and calculated $k_{\text {cat } 2 \text { values. }}$ 